\title{
The interactions of single-wall carbon nanohorns with polar epithelium
}

\author{
This article was published in the following Dove Press journal: \\ International Journal of Nanomedicine \\ I June 2017 \\ Number of times this article has been viewed
}

\author{
Yujie Shi, ' Zujin Shi, ${ }^{2}$ Suxin \\ Li,' Yuan Zhang, ${ }^{3}$ Bing He, ' \\ Dong Peng, ${ }^{4}$ Jie Tian, ${ }^{4}$ Ming \\ Zhao, ${ }^{5}$ Xueqing Wang, ' \\ Qiang Zhang' \\ 'Beijing Key Laboratory of \\ Molecular Pharmaceutics and New \\ Drug Delivery Systems, School of \\ Pharmaceutical Sciences, ${ }^{2}$ Beijing \\ National Laboratory for Molecular \\ Sciences, State Key Lab of Rare Earth \\ Materials Chemistry and Applications, \\ College of Chemistry and Molecular \\ Engineering, Peking University, \\ Beijing, People's Republic of China; \\ ${ }^{3}$ Department of Biomedical and \\ Pharmaceutical Sciences, College of \\ Pharmacy, University of Rhode Island, \\ Kingston, RI, USA; ${ }^{4}$ Key Laboratory \\ of Molecular Imaging of Chinese \\ Academy of Sciences, Institute of \\ Automation, Chinese Academy of \\ Sciences, ${ }^{5}$ Department of Chemical \\ Biology, School of Pharmaceutical \\ Sciences, Peking University, Beijing, \\ People's Republic of China
}

Correspondence: Ming Zhao

Department of Chemical Biology, School of Pharmaceutical Sciences, Peking University, Beijing 100191, People's Republic of China

Tel +86 I0 82801539

Email sunmoonzhao@sohu.com

Xueqing Wang

Beijing Key Laboratory of Molecular

Pharmaceutics and New Drug Delivery

Systems, School of Pharmaceutical

Sciences, Peking University, Beijing

I00191, People's Republic of China

Tel +86 I0 82805935

Email wangxq@bjmu.edu.cn
Abstract: Single-wall carbon nanohorns (SWCNHs), which have multitudes of horn interstices, an extensive surface area, and a spherical aggregate structure, offer many advantages over other carbon nanomaterials being used as a drug nanovector. The previous studies on the interaction between SWCNHs and cells have mostly emphasized on cellular uptake and intracellular trafficking, but seldom on epithelial cells. Polar epithelium as a typical biological barrier constitutes the prime obstacle for the transport of therapeutic agents to target site. This work tried to explore the permeability of SWCNHs through polar epithelium and their abilities to modulate transcellular transport, and evaluate the potential of SWCNHs in drug delivery. MadinDarby canine kidney (MDCK) cell monolayer was used as a polar epithelial cell model, and as-grown SWCNHs, together with oxidized and fluorescein isothiocyanate-conjugated bovine serum albumin-labeled forms, were constructed and comprehensively investigated in vitro and in vivo. Various methods such as transmission electron microscopy and confocal imaging were used to visualize their intracellular uptake and localization, as well as to investigate the potential transcytotic process. The related mechanism was explored by specific inhibitors. Additionally, fast multispectral optoacoustic tomography imaging was used for monitoring the distribution and transport process of SWCNHs in vivo after oral administration in nude mice, as an evidence for their interaction with the intestinal epithelium. The results showed that SWCNHs had a strong bioadhesion property, and parts of them could be uptaken and transcytosed across the MDCK monolayer. Multiple mechanisms were involved in the uptake and transcytosis of SWCNHs with varying degrees. After oral administration, oxidized SWCNHs were distributed in the gastrointestinal tract and retained in the intestine for up to $36 \mathrm{~h}$ probably due to their surface adhesion and endocytosis into the intestinal epithelium. Overall, this comprehensive investigation demonstrated that SWCNHs can serve as a promising nanovector that can cross the barrier of polar epithelial cells and deliver drugs effectively.

Keywords: carbon nanohorns, epithelial cells, transport mechanisms, nanocarriers, MSOT imaging

\section{Introduction}

Single-wall carbon nanohorns (SWCNHs) are 100- to 120-nm-sized, dahlia-like spherical particles aggregated by thousands of 2- to 3-nm-diameter tubes (Figure 1A). They are novel nanostructure carbon materials generating much enthusiasm in biomedical applications, such as drug delivery, photo-hyperthermia (due to their intrinsic therapeutic effects), and magnetic resonance analysis, due to their several advantages over other carbon materials such as single-walled carbon nanotubes. ${ }^{1-12}$ Besides their high purity, uniform size, and absence of metal catalysts, they have an extremely large specific surface area. ${ }^{8}$ Furthermore, their surface area can be enlarged, holes can be opened, and oxygen functional groups can be introduced by oxidation at their 
A

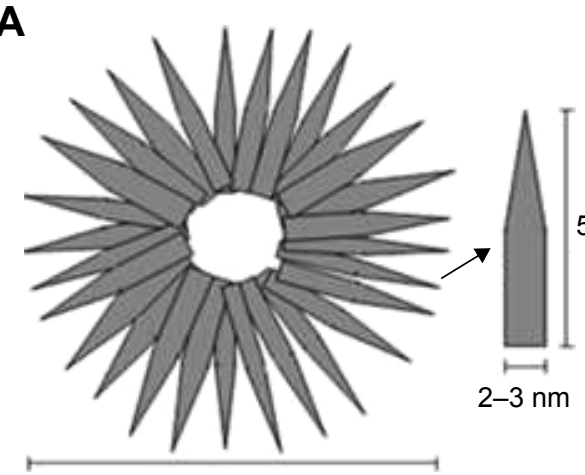

$80-100 \mathrm{~nm}$

agSWCNHs

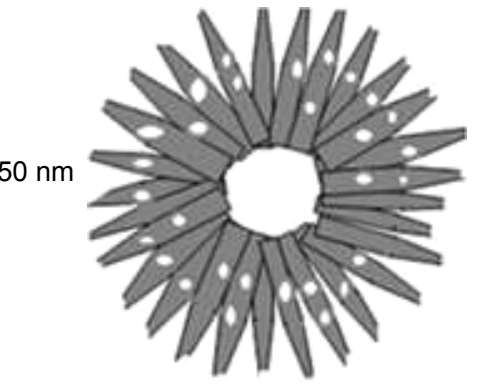

SWCNHox
B

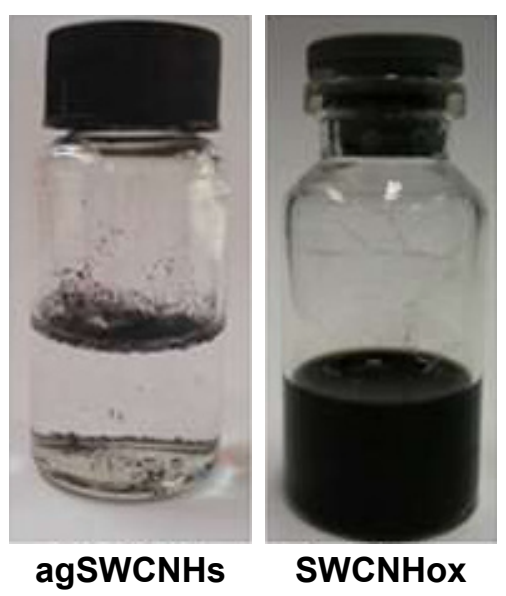

C
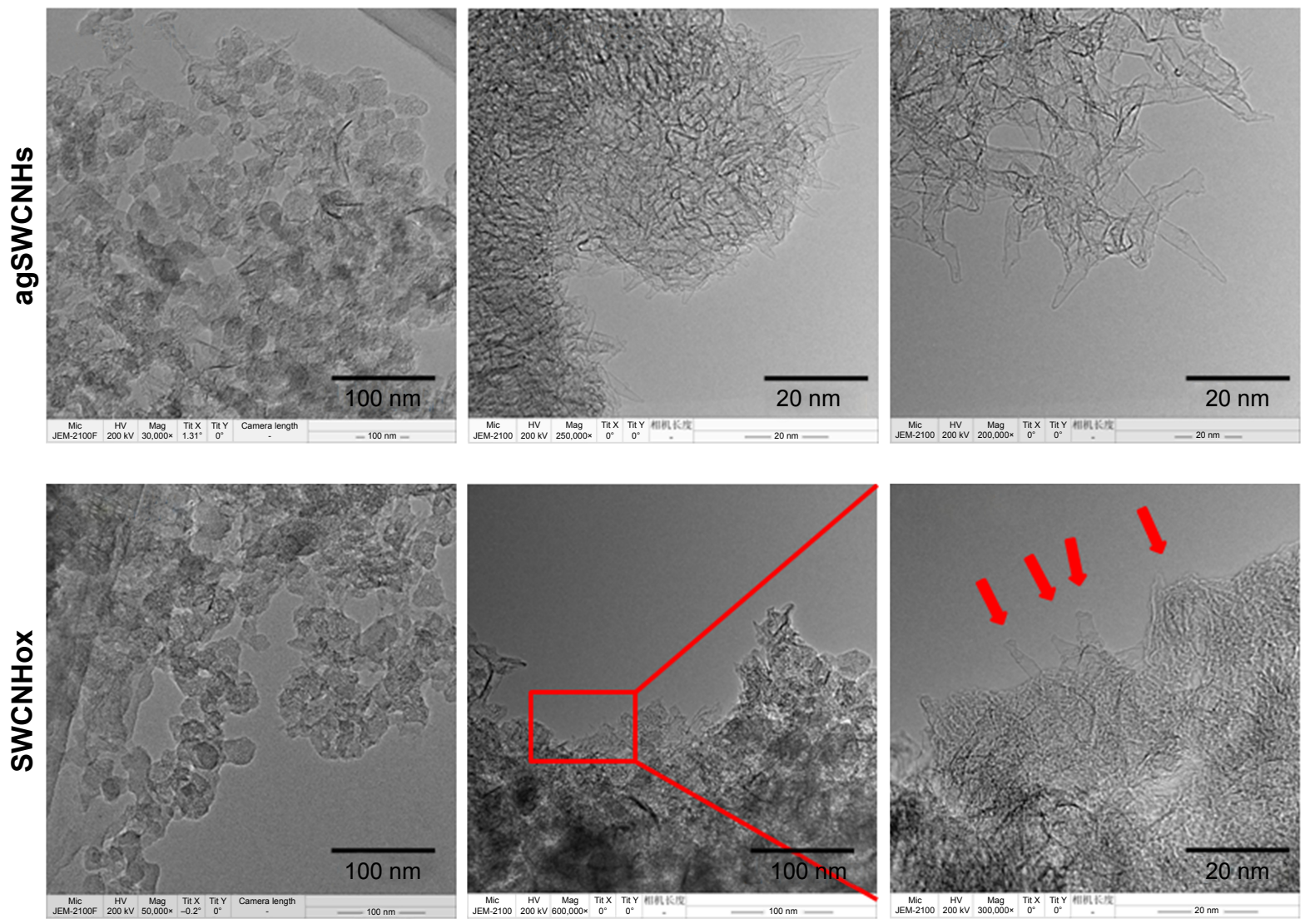

Figure I (A) Schematic structures of as-grown single-wall carbon nanohorns (agSWCNHs) and oxidized single-wall carbon nanohorns (SWCNHox); (B) Pictures of agSWCNHs and SWCNHox suspensions in water without suspending agent and probe ultrasound; (C) Transmission electron microscope photographs of agSWCNHs and SWCNHox.

Note: Red arrows indicate the opened holes on top tubes.

Abbreviation: SWCNH, single-wall carbon nanohorn.

defect sites such as pentagonal and heptagonal rings in the hexagonal networks. ${ }^{13}$ The extensive surface area and multitudes of horn interstices of SWCNHs enable large amounts of guest molecules to be adsorbed. Further, oxidized functional groups on the edges of the tube holes covalently attach with drugs and various functional molecules such as fluorescent probes. SWCNHs have shown a great potential as drug nanocarriers.

Until now, SWCNHs are primarily used for a controlled and sustained drug delivery in cancer therapy, focusing on the in vitro drug release as well as in vivo cancer targeted therapy and photo-hyperthermia. ${ }^{1-4,7-10}$ There are limited 
studies unveiling the interaction between SWCNHs and host with a particular emphasis on their mechanism involving polarized cells. Until now, studies at the cellular level on SWCNHs were mainly focused on the interaction between SWCNHs and non-polarized cells particularly macrophages, and have mostly emphasized on the cellular uptake and intracellular trafficking, but seldom on transportation. ${ }^{14-21}$ It is worth noting that, depending on the routes of administration, nanocarriers may have to cross different physiological barriers in their journey towards their target. ${ }^{22,23}$ These barriers are mainly polarized epithelia, such as the gastrointestinal tract, the lungs, and the blood-brain barrier. ${ }^{24-26}$ Not only that, when administered systemically, nanocarriers need to cross the endothelial cell barrier to reach the target site. A key element for the successful drug delivery by nanocarriers is their ability to either cross the biological barriers themselves or allow the loaded drugs to traverse these barriers to achieve an optimal pharmacological action at the pathological sites. ${ }^{22}$ However, little has been elucidated about the transportation of nanocarriers across the polarized epithelia. In particular, it is pointed out that there is almost no research on whether SWCNHs can transport across the epithelial barrier.

The transportation of nanocarriers across the polarized epithelial cellular barriers is achieved either by the paracellular route via transient disruption of the junctions that interlock the adjacent cells or by the transcellular route, where the materials are internalized by endocytosis, transported across the cell body, and secreted at the opposite cell surface (transcytosis). ${ }^{27-32}$ In the transcellular pathway, the nanocarriers can employ multiple mechanisms for cellular entry, including macropinocytosis, caveolae-mediated endocytosis, clathrin-dependent endocytosis, and clathrin- and caveolaeindependent endocytosis. ${ }^{28}$ The main factors influencing the interaction between the nanocarriers and cells include size, shape, charge, hydrophobicity of nanomaterials, and so on. ${ }^{28}$ The pathway through which SWCNHs with a special globular structure cross the epithelial barrier has not been studied yet either.

In particular, this study explores the interactions of SWCNHs with the polar epithelium. The focus of this work was to explore the transportation mechanisms of SWCNHs across the polar epithelium and their abilities to modulate transcellular transport, and evaluate the potential application of SWCNHs in drug delivery. The study shows that SWCNHs could serve as a promising drug delivery vehicle, as evidenced by their strong bioadhesion property, low cytotoxicity, and the way they are partially uptaken and transported across the endothelial cell barrier through multiple mechanisms. Madin-Darby canine kidney (MDCK) cell monolayer was used as an in vitro epithelial cell model. ${ }^{30-32}$ Based on the intrinsic properties of SWCNHs, photoacoustic imaging is the preferred method for tracking nanocarbons in vivo. Fast multispectral optoacoustic tomography (MSOT) imaging was used for monitoring the transport process of oxidized SWCNHs (SWCNHox) and validating their interaction with the intestinal epithelium in vivo. Three kinds of SWCNHs, as-grown SWCNHs (agSWCNHs), SWCNHox, and fluorescein isothiocyanate-conjugated bovine serum albumin (FITC-BSA)-labeled SWCNHox (F-B-SWCNHox), were studied in this work.

\section{Materials and methods \\ Materials}

agSWCNHs were synthesized in house. Fluorescent probes such as LysoTracker ${ }^{\mathrm{TM}}$ Red, Rhodamine-phalloidin, and Hoechst 33258 were products of Molecular Probes Inc. (Eugene, OR, USA). Bovine serum albumin (BSA; $66 \mathrm{kDa}$ ), nystatin, sucrose, chlorpromazine (CPZ), filipin, genistein, methyl-beta-cyclodextrin (M $\beta C D)$, 5-(N-ethyl$\mathrm{N}$-isopropyl)-amiloride (EIPA), dynasore, nocodazole, 1-ethyl-3-(3-dimethylaminopropyl) carbodiimide (EDC), N-hydroxysuccinimide (NHS), and glutaraldehyde solution were obtained from Sigma-Aldrich (St Louis, MO, USA). Cell counting kit-8 (CCK-8) was purchased from Dojindo Laboratories (Tokyo, Japan). FITC-BSA was purchased from Beijing Biodee Biotechnology Co. Ltd (Beijing, People's Republic of China). Transwells (12 wells, $3-\mu \mathrm{m}$ pore size, polycarbonate membranes), 96-microwell plates, 12-well plates, and 384-microwell plates were supplied by Corning Incorporated Costar (Corning, NY, USA). $\mathrm{H}_{2} \mathrm{O}_{2}$ was purchased from Sinopharm Chemical Reagent Co., Ltd (Beijing, People's Republic of China). Isoflurane was purchased from Hebei Yipin Pharmaceutical Co., Ltd (Shijiazhuang, People's Republic of China).

The MDCK cell line was obtained from the Institute of Basic Medical Science, China Academic Medical Science (Beijing, People's Republic of China). Dulbecco's Modified Eagle's Medium (DMEM; $4.5 \mathrm{~g} \mathrm{~L}^{-1}$ glucose) culture solution, phosphate-buffered saline (PBS), penicillinstreptomycin, and trypsin were obtained from Macgene Biotechnology Ltd. (Beijing, People's Republic of China). Fetal bovine serum (FBS) was purchased from Gibco, Invitrogen Corp. (Carlsbad, CA, USA). MDCK cells were cultured in high-glucose DMEM, supplemented with 10\% FBS and $1 \%$ penicillin-streptomycin, in a humidified 
atmosphere containing $5 \% \mathrm{CO}_{2}$ at $37^{\circ} \mathrm{C}$. The medium was refreshed every other day. Cells were passaged at $70 \%-90 \%$ confluency using $0.25 \%$ trypsin $/ 0.02 \%$ ethylene diamine tetraacetic acid.

$\mathrm{Nu} / \mathrm{Nu}$ nude mice were purchased from Vital Laboratory Animal Center (Beijing, People's Republic of China). Before experiment, they were kept under specific-pathogen-free condition for $\sim 1$ week and allowed free access to standard food and water. The housing facility was a barrier housing facility, and was in keeping with the national standard of People's Republic of China "Laboratory Animal - Requirements of Environment and Housing Facilities" (GB 14925 -2001). The care of the laboratory animals and the animal experimental operation conformed to the "Beijing Administration Rule of Laboratory Animal." All care and handling of animals were performed with the approval of Institutional Animal Care and Use Committee at Peking University (No LA2015156).

\section{Preparation of agSWCNHs, SWCNHox, and F-B-SWCNHox}

Preparation of agSWCNHs and SWCNHox

The agSWCNHs were synthesized in house by the arc discharge method without using any metal catalysts as described previously. ${ }^{33}$ The content of SWCNHs was $95 \%$, with the remaining $5 \%$ being graphitic particles. SWCNHox were prepared according to the reference with slight modifications. ${ }^{34}$ Briefly, $30 \mathrm{mg}$ of agSWCNHs was dispersed in $40 \mathrm{~mL}$ of $30 \% \mathrm{H}_{2} \mathrm{O}_{2}$ aqueous solution, stirred at $100^{\circ} \mathrm{C}$, and irradiated with a $300-\mathrm{W}$ ultraviolet lamp (wavelength, $365 \mathrm{~nm}$ ) for $2.5 \mathrm{~h}$. The resulting product was centrifuged at 90,000 $\mathrm{g}$ for 60 min (Avanti J-30I; Beckman Coulter, Brea, CA, USA), followed by washing with sterilized deionized water, and the precipitation was freeze-dried to obtain SWCNHox. Stock solutions were prepared by suspending agSWCNHs or SWCNHox in water or PBS with $10 \mathrm{mg} \mathrm{mL}^{-1} \mathrm{BSA}$ as a suspending agent, followed by centrifugal removal of the large aggregates.

\section{Preparation of F-B-SWCNHox and BSA-SWCNHox} Two milligrams of SWCNHox was dispersed in $2.5 \mathrm{~mL}$ PBS at $\mathrm{pH} 7.4$, and then $12 \mathrm{mg}$ EDC and $120 \mathrm{mg}$ NHS were added. After stirring for $2 \mathrm{~h}$, FITC-BSA $\left(300 \mu \mathrm{L}, 5 \mathrm{mg} \mathrm{mL}^{-1}\right)$ was added and stirred for another $24 \mathrm{~h}$. Free EDC, NHS, and FITC-BSA were removed by repeated centrifugation and washing with sterilized water. The absence of free BSA was confirmed by the disappearance of the BSA absorption band in the ultraviolet-visible spectrum (TU1900 ultraviolet and visible spectrophotometer; Beijing Purkinje General Instrument Co. Ltd., Beijing, People's Republic of China). The obtained FITC-labeled SWCNHox were dispersed in PBS with $10 \mathrm{mg} \mathrm{mL}^{-1}$ BSA as a suspending agent as described above.

The BSA-conjugated SWCNHox (BSA-SWCNHox) were also prepared by attaching BSA to SWCNHox, using the same process as described above.

\section{Characterization of agSWCNHs, SWCNHox, and F-B-SWCNHox}

The particle size and zeta potential of agSWCNHs and SWCNHox suspensions were determined by dynamic light scattering using a Malvern Zetasizer Nano ZS (Malvern, $\mathrm{UK}$ ) at $25^{\circ} \mathrm{C} . \mathrm{C}, \mathrm{H}$, and $\mathrm{N}$ elemental analysis of agSWCNHs and SWCNHox was carried out on a Vario ELIII Element Analyzer (Elementar Analysensysteme GmbH, Hanau, Germany). Infrared (IR) spectra of agSWCNHs and SWCNHox were measured in the spectrum region of $4,000-400 \mathrm{~cm}^{-1}$ by using a PerkinElmer Fourier transform infrared (FTIR) spectrophotometer (Thermo-Nicolet Nexus 470 FTIR spectrometer; Thermo Nicolet Corporation, Madison, WI, USA). Transmission electron microscope images and energy-dispersive spectrum (EDS) of SWCNHs and SWCNHox were obtained using a JEM2100F fieldemission high-resolution transmission electron microscope (JEOL Ltd.). The fluorescence images of F-B-SWCNHox were examined using a confocal laser scanning microscope (Leica TCS SP8; Leica Microsystems, Wetzlar, Germany) at an excitation wavelength of $488 \mathrm{~nm}$.

\section{Influence of agSWCNHs and SWCNHox on MDCK cells}

High-content analysis (HCA)

MDCK cells were seeded in 96-well plates at a density of $3 \times 10^{5}$ cells per well and incubated for $24 \mathrm{~h}$ at $37^{\circ} \mathrm{C}$. The culture medium was removed, and the cells were incubated with complete DMEM containing different concentrations of agSWCNHs and BSA-SWCNHox for $24 \mathrm{~h}$. In this experiment, BSA-SWCNHox were used instead of SWCNHox. Cells without any treatment were used as the control. The concentrations of SWCNHs in suspensions were determined by adding $100-\mu \mathrm{L}$ suspensions to a 96 -microwell plate and measuring the absorbance at $690 \mathrm{~nm}$ with a multifunctional microplate reader. After being rinsed with PBS three times, the cells were visualized with a high-content imaging system (Operetta; PerkinElmer, Waltham, MA, USA). The images under 40-fold optical lens were acquired with Opera 2.0 software. 
Scanning electron microscopy (SEM) analysis

MDCK cells were incubated with complete DMEM containing $100 \mu \mathrm{g} \mathrm{mL}^{-1}$ agSWCNHs or SWCNHox for $24 \mathrm{~h}$. At the end of incubation, the cells were rinsed with PBS, fixed with $0.05 \%$ glutaraldehyde, and observed by a scanning electron microscope (JEOL JSM-5600LV).

\section{Cell viability assay using CCK-8}

MDCK cells were cultured in a 96-well plate at a density of $5 \times 10^{3}$ cells per well in $200-\mu \mathrm{L}$ culture medium under $37^{\circ} \mathrm{C}$ and $5 \% \mathrm{CO}_{2}$. The cells were incubated with different concentrations of agSWCNHs and SWCNHox suspensions for $72 \mathrm{~h}$. In accordance with manufacturer's instruction, culture medium was removed, and the cells were further incubated with PBS containing the CCK-8 solutions for $2 \mathrm{~h}$. Finally, to eliminate the interference from SWCNHs, $100 \mu \mathrm{L}$ of the culture medium containing the CCK-8 solutions in each well was transferred to a new 96-well plate, and the optical density (OD) value in each well was measured at $450 \mathrm{~nm}$ with a multifunctional microplate reader.

\section{Cellular internalization of agSWCNHs, SWCNHox, and F-B-SWCNHox}

\section{Confocal image (fluorescence-labeling method)}

MDCK cells were seeded in flat-bottom 12-well plates at a density of $1 \times 10^{6}$ cells per well. When the cells reached confluency, $20 \mu \mathrm{g} \mathrm{mL}^{-1}$ F-B-SWCNHox in complete medium were added and incubated with the cells for $24 \mathrm{~h}$ at $37^{\circ} \mathrm{C}$ to allow endocytosis. To analyze the state of the probe and to assess the reliability of the method, both F-B-SWCNHox centrifugal supernatant $(20,664 \times g 30 \mathrm{~min})$ and the cells without any treatment were used as control. After incubation, single-cell suspension was obtained and dropped onto glass bottom culture dishes. The internalization of F-BSWCNHox was monitored under a bright-field confocal microscope at 488-nm excitation wavelength for detecting FITC. The images from bright-field and FITC channel were merged using the image acquisition software of Leica. The mean intracellular fluorescence intensity was analyzed with Leica Qwin software.

\section{Confocal image (reflected light-imaging method)}

MDCK cells were seeded in flat-bottom 12-well plates at a density of $1 \times 10^{6}$ cells per well. When the cells reached confluency, $20 \mu \mathrm{g} \mathrm{mL}^{-1}$ agSWCNHs and SWCNHox in complete medium were added and incubated with the cells for $24 \mathrm{~h}$ at $37^{\circ} \mathrm{C}$ to allow endocytosis. After incubation, single-cell suspension was obtained and dropped onto glass bottom culture dishes. The internalization of agSWCNHs and SWCNHox was monitored by a confocal laser scanning microscope (Leica TCS SP8) at $561 \mathrm{~nm}$, the wavelength at which the nanocarbon showed a strong reflect light. The images from agSWCNHs or SWCNHox and bright field were merged using the image acquisition software of Leica. The mean intracellular fluorescence intensity or reflected light intensity was analyzed with Leica Qwin software.

\section{Transmission electron microscope (TEM) analysis}

TEM analysis was conducted to observe the internalization of agSWCNHs and SWCNHox by MDCK cells. Cells without any treatment were used as the control. After 24-h incubation with $50 \mu \mathrm{g} \mathrm{mL}^{-1}$ agSWCNHs or SWCNHox in complete medium at $37^{\circ} \mathrm{C}$, the cells were rinsed and dissociated into single-cell suspensions. Then, they were fixed with $4 \% \mathrm{OsO}_{4}$ and observed by a transmission electron microscope (JEM1400 Plus electron microscope; JEOL Ltd.).

\section{Endocytosis mechanism studies}

Different inhibitors were explored to study the endocytosis pathways of SWCNHox. The concentrations of different inhibitors are shown in Table 1, and the influences of these inhibitors on cell viability were detected using CCK-8 assay. ${ }^{32}$ In the endocytosis pathway study, MDCK cells were pre-incubated with serum-free DMEM containing inhibitors for $1 \mathrm{~h}$ in a 12-well plate, and then the medium was removed and replenished with serum-free DMEM containing $100 \mu \mathrm{g} \mathrm{mL}^{-1}$ SWCNHox with homologous inhibitors and the cells were incubated for another $2 \mathrm{~h}$. Cells without inhibitor treatment were used as the control. After incubation, the cells in SWCNHox groups were dissociated into

Table I The function and concentration of inhibitors used for endocytosis study

\begin{tabular}{|c|c|c|}
\hline Inhibitors & Function & Concentration \\
\hline Chlorpromazine & $\begin{array}{l}\text { Inhibitor of clathrin- } \\
\text { mediated endocytosis }\end{array}$ & $30 \mu \mathrm{M}$ \\
\hline $\begin{array}{l}\text { Hypertonic } \\
\text { sucrose }\end{array}$ & $\begin{array}{l}\text { Inhibitor of clathrin- } \\
\text { mediated endocytosis }\end{array}$ & $0.4 \mathrm{M}$ \\
\hline $\mathrm{M} \beta \mathrm{CD}$ & Depletion of cholesterol & $10 \mathrm{mM}$ \\
\hline Nystatin & Depletion of cholesterol & $30 \mu \mathrm{M}$ \\
\hline Filipin & $\begin{array}{l}\text { Inhibitor of caveolae- } \\
\text { mediated endocytosis }\end{array}$ & $0.5 \mu \mathrm{g} \mathrm{mL} \mathrm{L}^{-1}$ \\
\hline EIPA & Inhibitor of macrocytosis & $20 \mu \mathrm{M}$ \\
\hline Genistein & $\begin{array}{l}\text { Inhibitor of tyrosine- } \\
\text { specific protein kinases }\end{array}$ & $100 \mu \mathrm{M}$ \\
\hline Dynasore & $\begin{array}{l}\text { Inhibitor of cell- } \\
\text { permeable dynamin }\end{array}$ & $20 \mu \mathrm{g} \mathrm{mL^{-1 }}$ \\
\hline Nocodazole & Mitotic inhibitor & $12.5 \mu \mathrm{g} \mathrm{mL} \mathrm{L}^{-1}$ \\
\hline
\end{tabular}


single-cell suspensions as described above and observed using a confocal laser scanning microscope by reflected light method.

The influence of temperature on cellular uptake was also studied. MDCK cells were grown in 12-well plates. After pre-incubating with serum-free DMEM for $40 \mathrm{~min}$ at $4^{\circ} \mathrm{C}$ or $37^{\circ} \mathrm{C}$, the cells were treated with $100 \mu \mathrm{g} \mathrm{mL} \mathrm{m}^{-1}$ agSWCNHs or SWCNHox suspensions in serum-free DMEM at $4^{\circ} \mathrm{C}$ or $37^{\circ} \mathrm{C}$ for $4 \mathrm{~h}$, respectively. The cells were subsequently dissociated into single-cell suspensions as described above, and then observed using a confocal laser scanning microscope with the reflected light method. Quantitative analysis was carried out with Leica Qwin software.

\section{Intracellular trafficking analysis}

Colocalization of lysosomes was studied to investigate the contribution of lysosomes to the intracellular trafficking of carbon nanohorns. MDCK cells were seeded on glass bottom dishes, and then they were incubated with $100 \mu \mathrm{g} \mathrm{mL}^{-1} \mathrm{agSW}-$ CNHs and SWCNHox in complete medium for $24 \mathrm{~h}$. Then, the medium was removed, and pre-warmed LysoTrackerTM Red-containing medium was added. After 2-h incubation, the cells were washed and observed by confocal laser scanning microscopy (CLSM). Colocalization ratio was determined using LAS AF software (Leica Microsystems, Heidelberg, Germany). TEM was also used to monitor the intracellular trafficking of agSWCNHs and SWCNHox.

\section{Transcellular demonstration of agSWCNHs, SWCNHox, and F-B- SWCNHox through MDCK cell \\ monolayer \\ MDCK cell monolayer culture}

MDCK cells were seeded on a polycarbonate membrane (Transwell $^{\circledR}, 12$ wells; Corning Incorporated Costar) at a density of $2 \times 10^{5}$ cells per well. Then, $0.5 \mathrm{~mL}$ DMEM was added into the upper compartment of transwell insert, while $1.5 \mathrm{~mL}$ was added to its basolateral side. Media in both upper and basilar compartments were changed every 2 days, and the transepithelial electrical resistance (TEER) was measured by an epithelial Volt-Ohm Meter (Millicell ${ }^{\circledR}$ ERS-2; EMD Millipore). At the end of 7-day culture, the cell monolayers with a TEER value above $180 \Omega$ were selected for the subsequent studies. ${ }^{32}$

Quantitative detection of transcellular agSWCNHs, SWCNHox, and F-B-SWCNHox

For quantitative detection, $20 \mu \mathrm{g} \mathrm{mL}^{-1}$ of agSWCNHs, SWCNHox, or F-B-SWCNHox in complete medium was incubated with monolayer at $37^{\circ} \mathrm{C}$. At predesigned time points, the medium in the basolateral chamber was collected, and the amounts of transported nanomaterials were determined by a multifunctional microplate reader based on the visible-light absorption of SWCNHs. Briefly, $10 \mu \mathrm{L}$ of each suspension was added to a 384-microwell plate, and the OD of each well was measured with a multifunctional microplate reader (FlexStation3; Molecular Devices) at $690 \mathrm{~nm}$. The amount of SWCNHs was calculated according to a predetermined calibration curve. The transported SWCNHox at predesigned concentration and time points were also monitored using the same method.

\section{Confocal image series of the transportation of F-B-SWCNHox through MDCK cell monolayer}

MDCK cell monolayer was incubated with $40 \mu \mathrm{g} \mathrm{mL}^{-1} \mathrm{~F}-\mathrm{B}-$ SWCNHox for $12 \mathrm{~h}$. Cell culture media from both the apical and basolateral transwells were collected at predetermined time points. Then, the monolayers on transwell were incubated with Hoechst 33342 and LysoTrackerTM Red to label the cell nuclei and lysosome separately for $2 \mathrm{~h}$. Transwell was then washed with PBS buffer three times, and removed onto a glass-bottom culture dish. The medium collected previously of the apical chamber of transwell was added back, and the medium in the basolateral chamber collected previously was added carefully to the glass-bottom culture dish. Then, the dish was put into the stage and viewed under a Leica TCS SP8 confocal laser scanning microscope in $\mathrm{X}-\mathrm{Y}-\mathrm{Z}$ scanning mode. Serial sections along the $\mathrm{Z}$-axis, from the upper side of the transwell to the bottom of the dish, were used to localize the F-B-SWCNHox. Serial sections along the $\mathrm{Y}$-axis were also acquired. The processing and visualization of three-dimensional (3D) reconstruction images was performed using the Leica software. The medium in basolateral chamber was collected and centrifuged. The deposit was suspended in 20 - to $40-\mu \mathrm{L}$ medium, and then dropped onto a dish and imaged by CLSM.

\section{Evaluation of MDCK cell monolayer integrity}

To investigate whether agSWCNHs, SWCNHox, or F-BSWCNHox could influence the integrity of MDCK cells, complete media containing $20 \mu \mathrm{g} \mathrm{mL}^{-1}$ of the mentioned materials were added to the apical side of the cell monolayer and incubated with the cells for $6 \mathrm{~h}$. The TEER was examined at designated time points. The TEER of the monolayer was also monitored after the treatments with different concentrations of SWCNHox $\left(20,40,60\right.$, and $\left.80 \mu \mathrm{g} \mathrm{mL}{ }^{-1}\right)$ for $24 \mathrm{~h}$. TEM analysis was also conducted to observe the influence of SWCNHox on MDCK monolayer. SWCNHox and the tight junctions of monolayer were observed by TEM. 
Study of the mechanism of the transcellular process of SWCNHox

The transcytosis mechanism was studied by using different inhibitors. The monolayer integrity was monitored by TEER after the treatment with inhibitors. The monolayers were preincubated with different inhibitors for $40 \mathrm{~min}$. The incubation medium was then aspirated, and $100 \mu \mathrm{g} \mathrm{mL}^{-1}$ of SWCNHox with or without different inhibitors was added to the apical compartment and incubated with cells for $2 \mathrm{~h}$. At the end of incubation, medium in basolateral chamber was collected, and the amount of the nanomaterials was determined by a multifunctional microplate reader as described above.

\section{In vivo transportation after oral administration of SWCNHox suspension to nude mice}

The absorption spectrum of SWCNHox in the range of 680-980 nm was obtained using a UV-vis-NIR spectrophotometer (Cary-5000, Varian, Palo Alto, USA). In a phantom study by MSOT, the photoacoustic signal of SWCNHox at wavelengths of $680-950 \mathrm{~nm}$ was measured. A Nu/Nu nude mouse was orally administered with SWCNHox suspension at a single dose of $403.2 \mu \mathrm{g}\left(400 \mu \mathrm{L}, 1.008 \mathrm{mg} \mathrm{mL}^{-1}\right)$. Photoacoustic images were acquired prior to oral gavage and then acquired at scheduled time points post-oral gavage. The in vivo distribution of the SWCNHox was monitored using an MSOT small animal-imaging apparatus (iThera Medical GmbH, Munich, Germany). Images were acquired by scanning the thoracoabdominal region with $0.5-\mathrm{mm}$ steps, six wavelengths $(700,730,760,800,850$, and $900 \mathrm{~nm})$, and 20 averages per wavelength. Anesthesia was maintained with $1.8 \%$ isoflurane in oxygen throughout the acquisitions. The mean photoacoustic signal in the region of interest was calculated for each photoacoustic image.

\section{Statistical analysis}

All statistical analyses were performed using the SPSS 13.0 software for windows (SPSS). Quantitative data are expressed as the mean \pm standard deviation values. A one-way analysis of variance was conducted to evaluate the significance of results. A $P$-value of less than 0.05 was considered to be statistically significant.

\section{Results}

\section{Preparation of SWCNHox and F-B-SWCNHox}

agSWCNHs were synthesized by the arc discharge method, and were hydrophobic and poorly dispersed (Figure 1B). ${ }^{33}$ To improve their hydrophilicity, their surface area was enlarged, and functional groups were introduced. agSWCNHs were treated with light-assisted oxidation, and SWCNHox were prepared. ${ }^{34}$ SWCNHox were stable and homogeneously dispersed in water (Figure 1B). In order to precisely compare the structure and property of SWCNHs before and after oxidation, both agSWCNHs and SWCNHox were suspended in $10 \mathrm{mg} \mathrm{mL}^{-1} \mathrm{BSA}$ as a suspending agent, followed by probe ultrasound and centrifugation to separate the aggregated SWCNHs. Since FITC-BSA was widely used as a fluorescent marker to investigate the nanoparticle transport through biological barriers in vitro or in vivo, FITC-BSA was attached to the carboxyl groups of SWCNHox via diimide-activated amidation and used for tracing SWCNHox..$^{10,35,36}$

\section{Characterization of agSWCNHs, SWCNHox, and F-B-SWCNHox}

\section{Morphology and EDS analysis}

TEM observation revealed that agSWCNHs and SWCNHox were spherical in shape (Figure 1C), and that SWCNHox had holes in their walls. EDS results verified that the oxidation treatment did not introduce new elements to SWCNHs, and only changed the contents of existing elements (Figure S1). The images of SWCNHox showed that they were in an aggregated state although they were functionalized with hydrophilic groups to achieve better dispersibility than agSWCNHs, the pristine forms.

\section{Elemental analysis and FTIR}

Due to the introduction of oxygenated groups such as carboxylic acids, the content of both carbon and nitrogen elements reduced, while that of $\mathrm{H}$ element increased after oxidation treatment (Table S1). Oxygenated groups were present in SWCNHox, as identified from the additional absorption peaks present along with broad peaks in IR spectrum between 1,600 and $1,800 \mathrm{~cm}^{-1}$ which corresponded to $\mathrm{C}=\mathrm{O}$ stretching vibrations (Figure $\mathrm{S} 2 \mathrm{~A}$ ).

\section{Size and zeta potential}

After oxidation treatment, the dispersion and stability of SWCNHs were improved (Table S2 and Figure S2B). The zeta potentials of agSWCNHs and SWCNHox in water suspensions were $-26.1 \pm 0.51$ and $-22.5 \pm 0.85 \mathrm{mV}$, respectively (Figure S2C).

\section{Fluorescence spectrum}

The labeled FITC did not induce an increase of background fluorescence of treated cells; therefore, the green fluorescence observed basically represented the F-B-SWCNHox (Figure $\mathrm{S} 3$ ). ${ }^{35}$ The fluorescence spectrum of F-B-SWCNHox 
suspensions in complete culture medium confirmed their successful construction (Figure S3C).

\section{Influence of agSWCNHs and SWCNHox on MDCK cells}

The bioadhesion of agSWCNHs and SWCNHox on MDCK cells was firstly observed by HCA. As shown in Figure 2A, a lot of black particles were adsorbed on MDCK cells after incubation with agSWCNHs and SWCNHox in DMEM containing $10 \% \mathrm{FBS}$ for $24 \mathrm{~h}$ at $37^{\circ} \mathrm{C}$, and the black spots on the surface of the cells increased with the increasing concentration of SWCNHs. The agSWCNHs group showed more aggregates compared to the SWCNHox group. Bioadhesion and accumulation of agSWCNHs and SWCNHox on cultured cells in serum-free medium were in accordance with the results obtained for cells in serumcontaining medium. The results of SEM further showed that the SWCNHs aggregated on the surface of the cells, and
A
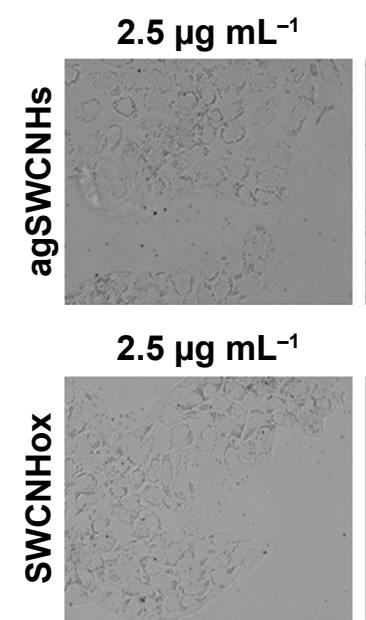

B

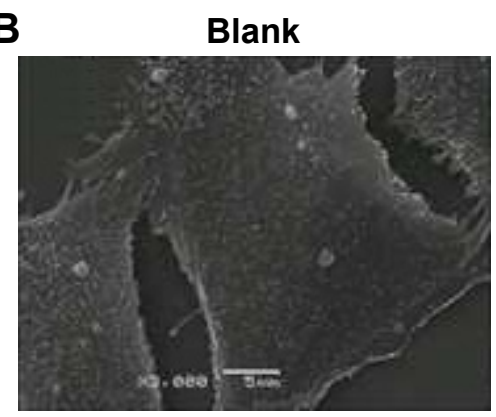

C

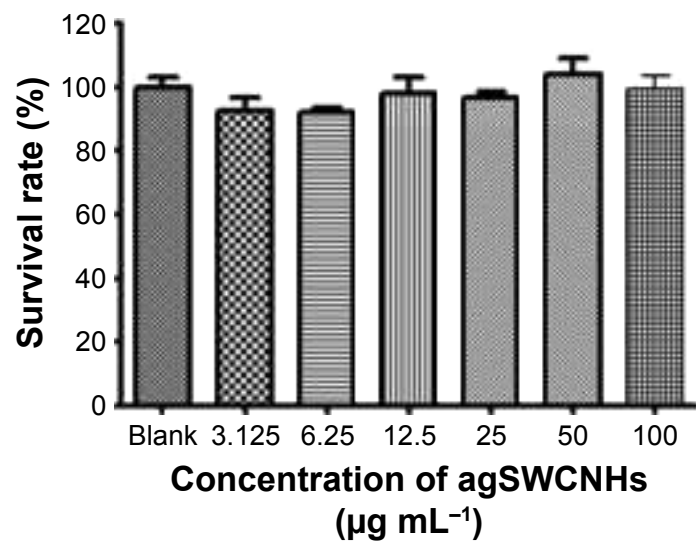

$25 \mu \mathrm{mL}^{-1}$

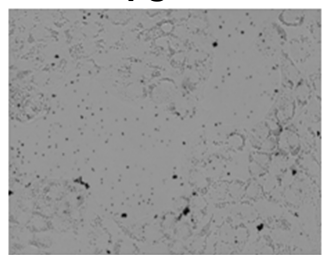

$25 \mu \mathrm{mL}^{-1}$
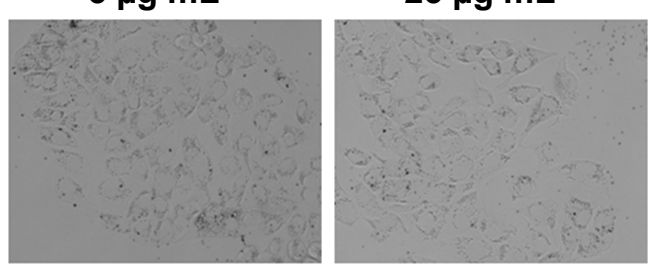

$100 \mu \mathrm{g} \mathrm{mL}^{-1}$

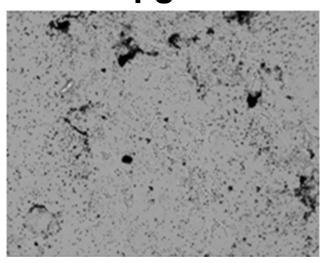

$100 \mu \mathrm{mL}^{-1}$

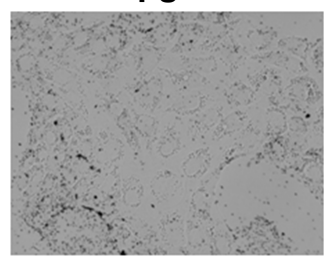

SWCNHox

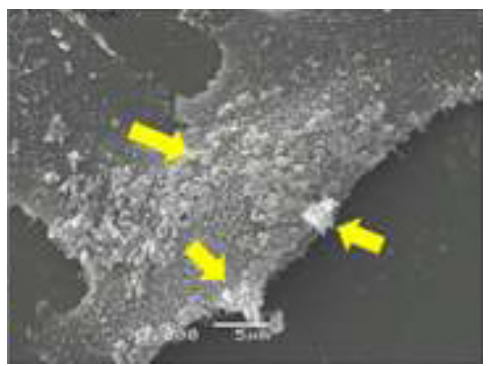

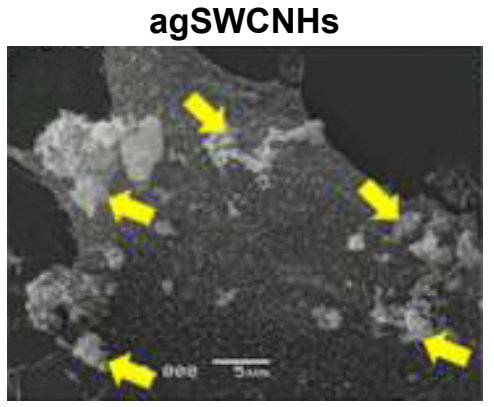

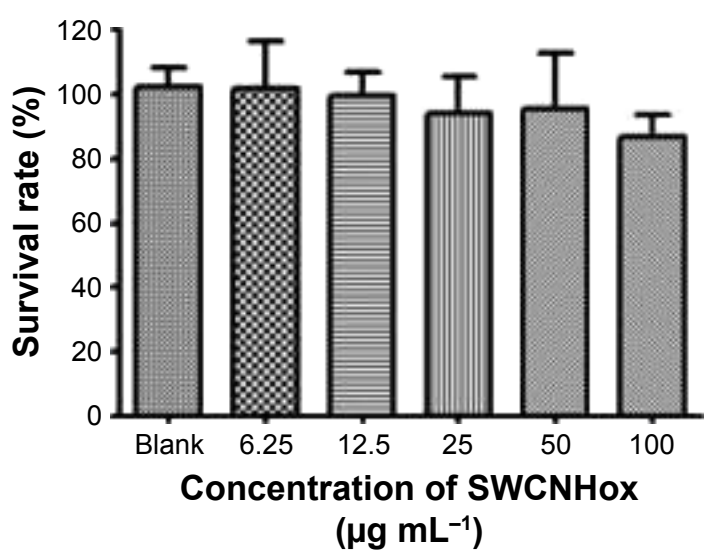

Figure 2 (A) Bright field graphs (40x magnification) of MDCK cells by high content imaging system. Cells were exposed to different concentrations of agSWCNHs and SWCNHox in DMEM containing $10 \% \mathrm{FBS}$ at $37^{\circ} \mathrm{C}$ for $24 \mathrm{~h}$; (B) SEM graphs of MDCK cells without any treatment, or incubated with $100 \mu \mathrm{g} \mathrm{mL}^{-1}$ agSWCNHs and SWCNHox suspensions at $37^{\circ} \mathrm{C}$ for $24 \mathrm{~h}$, respectively. Arrows indicate the aggregations of agSWCNHs or SWCNHox; (C) The influence of agSWCNHs and SWCNHox on the viability of MDCK cells after $72 \mathrm{~h}$ treatment, measured by CCK-8 kit. Scale bars for images in Figure $2 \mathrm{~B}$ are $5 \mu \mathrm{m}$.

Abbreviations: SWCNH, single-wall carbon nanohorn; MDCK, Madin-Darby canine kidney; FBS, fetal bovine serum; DMEM, Dulbecco's Modified Eagle's Medium; SEM, scanning electron microscope; CCK-8, Cell counting kit-8. 
agSWCNHs were more prone to integrate larger clumps (Figure 2B). The cell viability after exposure to agSWCNHs or SWCNHox at the concentration of $100 \mu \mathrm{g} \mathrm{mL}^{-1}$ for $72 \mathrm{~h}$ was determined by CCK-8 assay. Little effect on the viability of the polar epithelial cells was observed in both agSWCNHs and SWCNHox group (Figure 2C). These results indicated that agSWCNHs and SWCNHox exhibited relatively high bioadhesion and low cytotoxicity to MDCK cells.

\section{Cellular internalization of agSWCNHs, SWCNHox, and F-B-SWCNHox Confocal image}

Fluorescence-labeling method and reflected light method were used to investigate the cellular uptake of SWCNHs. Figure 3A shows the confocal images of cellular internalization of F-B-SWCNHox and their controls. Fluorescence spots, both on the surface of cell membranes and in the cytoplasm of MDCK cells, were observed in the F-B-SWCNHox group, which confirmed the internalization of F-B-SWCNHox, while, in the blank cells and F-B-SWCNHox centrifugal supernatant-treated group, no fluorescence spots were found. The fluorescence intensity of the three groups is shown in Figure 3B. The F-B-SWCNHox group showed significantly higher fluorescence intensity than the other two groups.

Reflected light method was also used to investigate the cellular uptake of agSWCNHs and SWCNHox (Figure 3C). The statistical results (Figure 3D) showed that the intensity of reflected light in SWCNHox-treated cells was significantly greater than that of agSWCNHs-treated cells. Additionally, agSWCNHs were mainly adsorbed on the surface of MDCK cells, while SWCNHox were prone to internalization, due to the hydrophilic enhancement of SWCNHox after oxidation. As shown in Figure 1B, the oxidation allowed SWCNHox to be more easily dispersed than agSWCNHs.

\section{TEM analysis}

The TEM imaging was used to visualize the internalization process and the subcellular location of agSWCNHs and SWCNHox. As indicated in TEM images, large clusters were observed in cells treated with either agSWCNHs (Figure 4) or SWCNHox (Figure 5), and spherical aggregation and carbon atomic lattice fringes were observed from the enlarged graphs (Figure 4B and E and Figure 5B, C, E, and H-I). Uptake of spherical-shaped materials into vesicles was a rare event for agSWCNHs-treated group, while that event was found in SWCNHox-treated group (Figure 5C). Poor dispersion in cell medium may explain these observations, even though one cannot exclude that these agglomerates were formed inside cells.

\section{Intracellular trafficking analysis}

To illustrate the intracellular transport destination, the colocalization between agSWCNHs or SWCNHox and lysosomes was studied. As indicated in Figure 3E, both agSWCNHs and SWCNHox were found to colocalize with lysosomes after incubation for $24 \mathrm{~h}$. According to the colocalization rate analysis, SWCNHox had a significantly higher colocalization rate than agSWCNHs (Figure 3F). TEM images were also used to observe the fine distribution of agSWCNHs or SWCNHox in cells. They were found to accumulate in the cytoplasmic membrane-bound vesicles. Typical intracellular locations of agSWCNHs or SWCNHox included compartments along the endo-lysosomal pathway, such as endosomes (Figure 4G and $\mathrm{H}$ and Figure 5A, B, D, and $\mathrm{E}$ ), large vesicular structures (Figure $4 \mathrm{~B}, \mathrm{C}$, and $\mathrm{F}$ and Figure 5G-I), and lysosomes (Figures $4 \mathrm{I}$ and $5 \mathrm{~F}$ ). This is consistent with many other nanomaterials taken up by other cell types, whose final intracelluar destination is often the lysosomes. ${ }^{37,38}$

\section{Endocytosis mechanism studies}

The effect of the temperature on uptake was observed. agSWCNHs and SWCNHox accumulated intensively around the cell membranes but not inside the cells at $4^{\circ} \mathrm{C}$, while they internalized into cells at $37^{\circ} \mathrm{C}$ (Figure $6 \mathrm{~A}$ and $\mathrm{B}$ ), indicating that the cell internalization was an energy-dependent and active transport process.

Various endocytosis inhibitors were utilized to identify the pathway involved in the cellular internalization of SWCNHox (Table 1). ${ }^{39}$ No significant cytotoxicity was observed for any of the pharmacological agents at the given doses (Figure S4). Confocal images of the cellular adhesion and uptake of SWCNHox after the treatment with inhibitors are shown in Figure 6C and D. The cellular adhesion and uptake of SWCNHox in the presence of nocodazole (a microtubule-depolymerizing agent) remained unaffected, suggesting that disruption of microtubules with nocodazole had a little effect on endocytosis. The inhibition effect of $M \beta C D$, nystatin, and filipin demonstrated that the endocytosis process of SWCNHox was highly cholesterol dependent. ${ }^{31,32}$ Cell adhesion and internalization was also significantly reduced by genistein, a specific inhibitor of tyrosine kinase, indicating that the tyrosine kinase pathway is involved in endocytosis. Prominent reduction occurred when the cells were pre-incubated with CPZ or hypertonic sucrose, which was suggestive of clathrin-mediated endocytosis (CME). ${ }^{31}$ EIPA, a specific inhibitor of macropinocytosis, significantly affected the cell adhesion and uptake in a negative way, indicting the participation of macropinocytosis pathway 

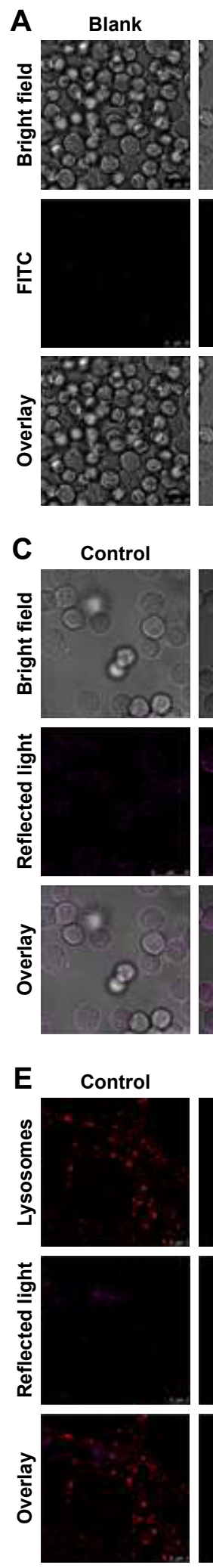

Supernatant
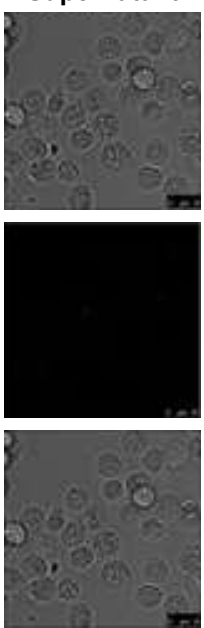

agSWCNHs
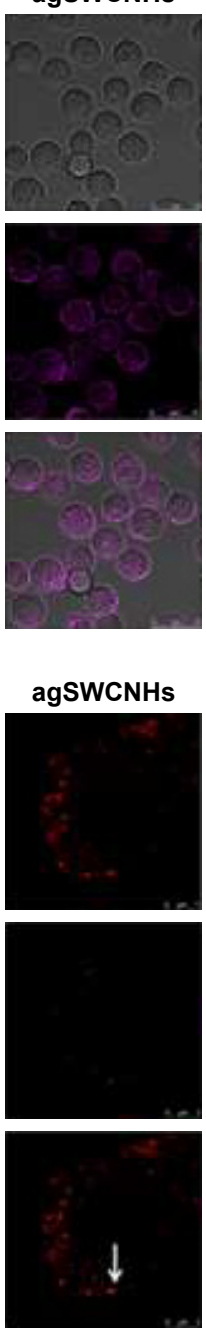

F-B-SWCNHox
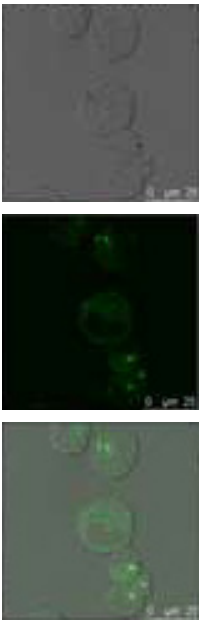

\section{SWCNHox}
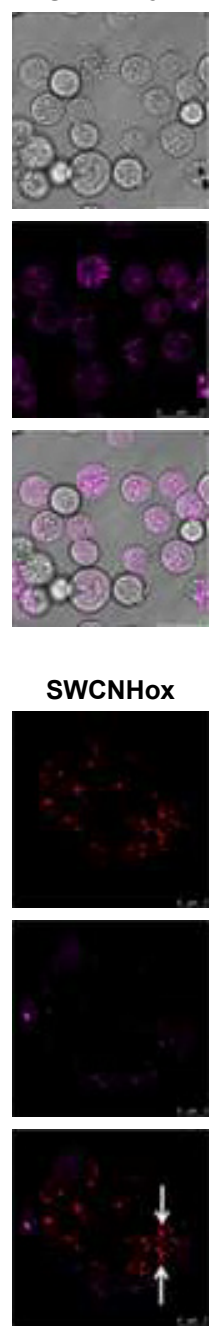

B
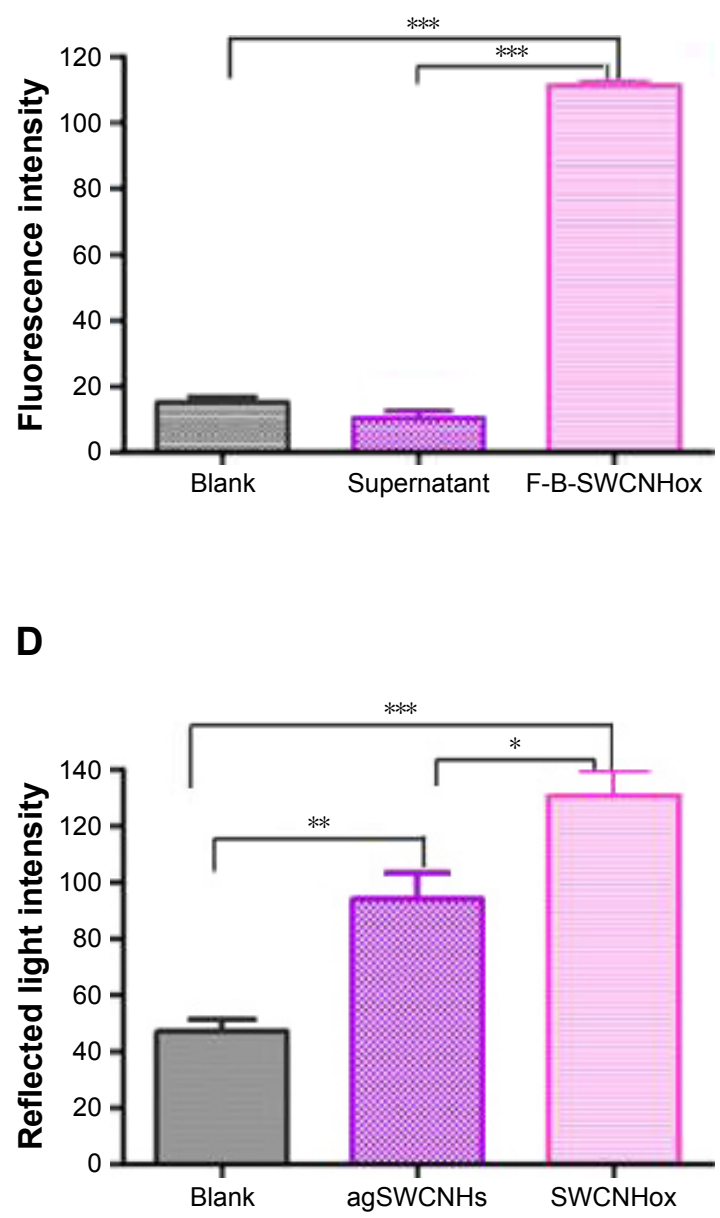

F

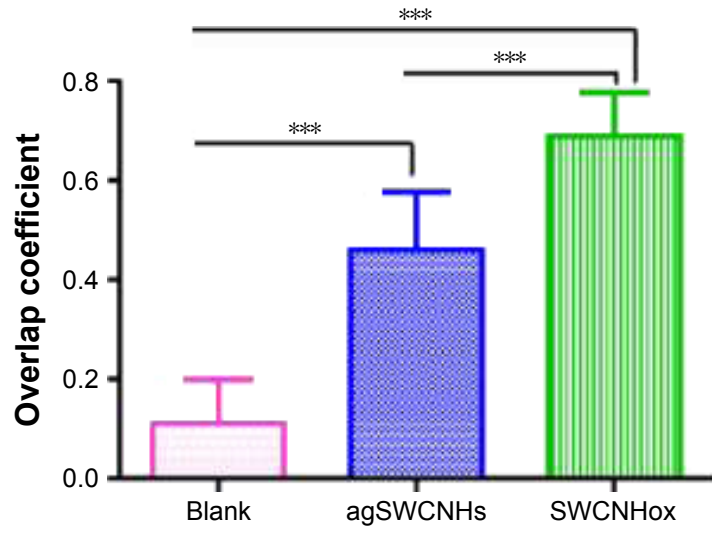

Figure 3 (A) CLSM images of digestive suspension MDCK cells after 24-h incubation with serum containing DMEM (control), supernatant of the FITC-BSA- conjugated SWCNHox (F-B-SWCNHox) suspension (supernatant control) or $20 \mu \mathrm{g} \mathrm{mL}-1$ F-B-SWCNHox suspension; (B) The mean intracellular fluorescence intensity of control, supernatant and F-BSWCNHox analyzed with Leica Qwin software. ${ }^{* *} * \mathrm{P}<0.000$ I; (C) Digestive suspension MDCK cells exposed to serum containing DMEM, $20 \mu g \mathrm{~mL}^{-1}$ agSWCNHs or SWCNHox observed by CLSM with reflected light at $56 \mathrm{Imm}$. Scale bars in the images are $25 \mu \mathrm{m}$; (D) The mean intracellular reflected light intensity of control, agSWCNHs and SWCNHox analyzed with Leica Qwin software. $* P<0.05$; $* * P<0.0$ I; $* * * P<0.00$ I; (E) Colocalization of lysosomes with control or $100 \mu g \mathrm{~mL}^{-1}$ agSWCNHs or SWCNHox, white arrows indicate the nanoparticles colocalized with lysosomes; (F) Quantitative colocalization analysis of agSWCNHs and SWCNHox with lysosomes using LAS AF software $* * * P<0.000 \mathrm{I}$. Magenta presents the pseudo-color of reflected light of SWCNHs in $\mathbf{C}$ and $\mathbf{E}$. Scale bars for images in $\mathbf{A}$ and $\mathbf{C}$ are $25 \mu \mathrm{m}$, scale bars for images in $\mathbf{E}$ are $5 \mu \mathrm{m}$.

Abbreviations: SWCNH, single-wall carbon nanohorn; agSWCNH, as-grown single-wall carbon nanohorns; SWCNHox, oxidized single-wall carbon nanohorns; CLSM, confocal laser scanning microscope; DMEM, Dulbecco's Modified Eagle's Medium; FITC, fluorescein isothiocyanate; FITC-BSA, FITC-conjugated bovine serum albumin. 

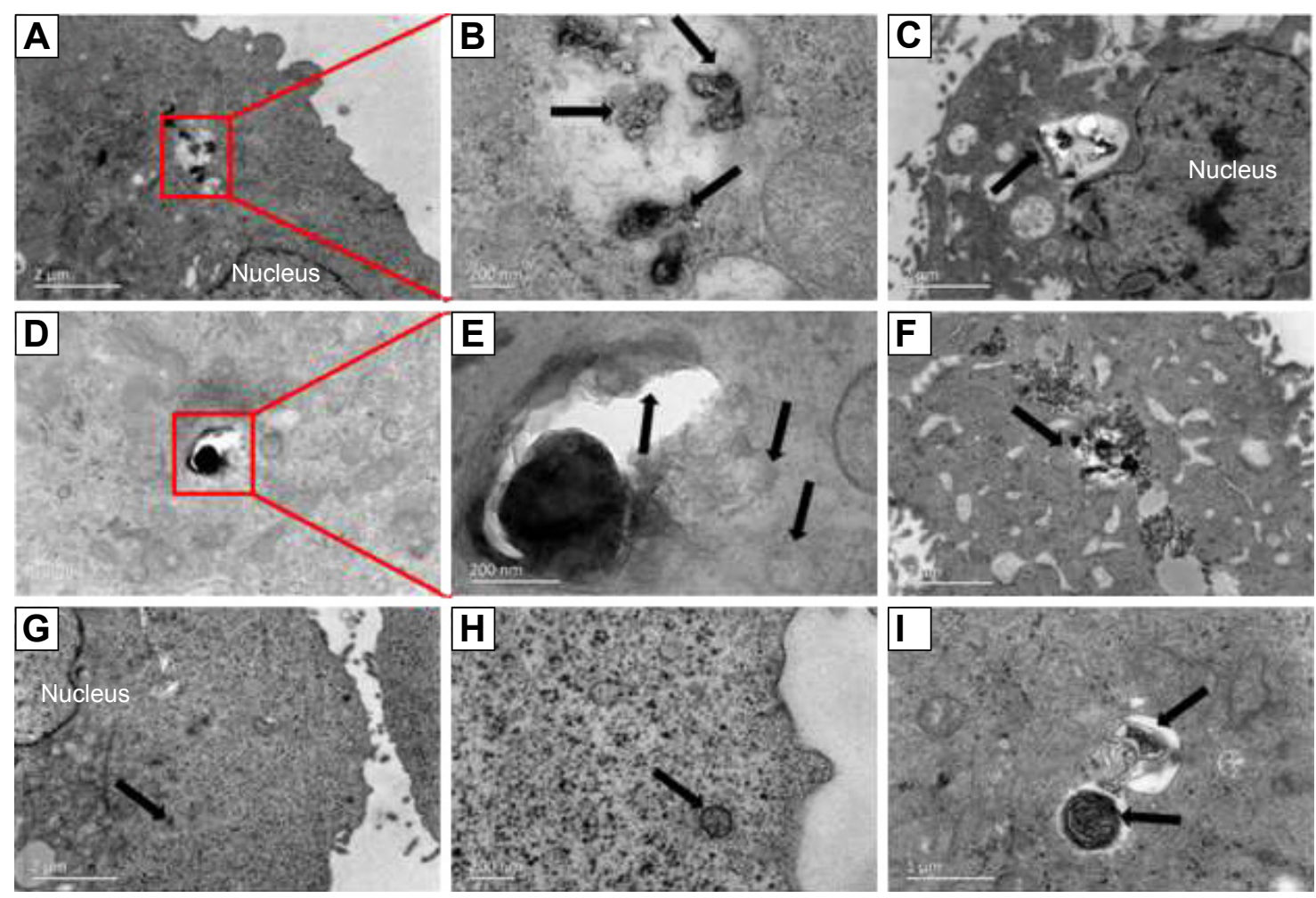

Figure $4 \mathrm{TEM}$ graphs of MDCK cells incubated with $50 \mu \mathrm{g} \mathrm{mL}-1$ agSWCNHs suspensions at $37^{\circ} \mathrm{C}$ for $24 \mathrm{~h}$. Arrows indicate the internalized agSWCNHs. (A, B D, E) Cytoplasmic vesicles full of agSWCNHs; (B, C, F) Internalized agSWCNHs clustered in large vesicular structures; (G, H), agSWCNHs in an endosomal vesicle; (I) agSWCNHs in lysosomes.

Abbreviations: TEM, transmission electron microscope; SWCNH, single-wall carbon nanohorn; MDCK, Madin-Darby canine kidney; agSWCNH, as-grown single-wall carbon nanohorns.
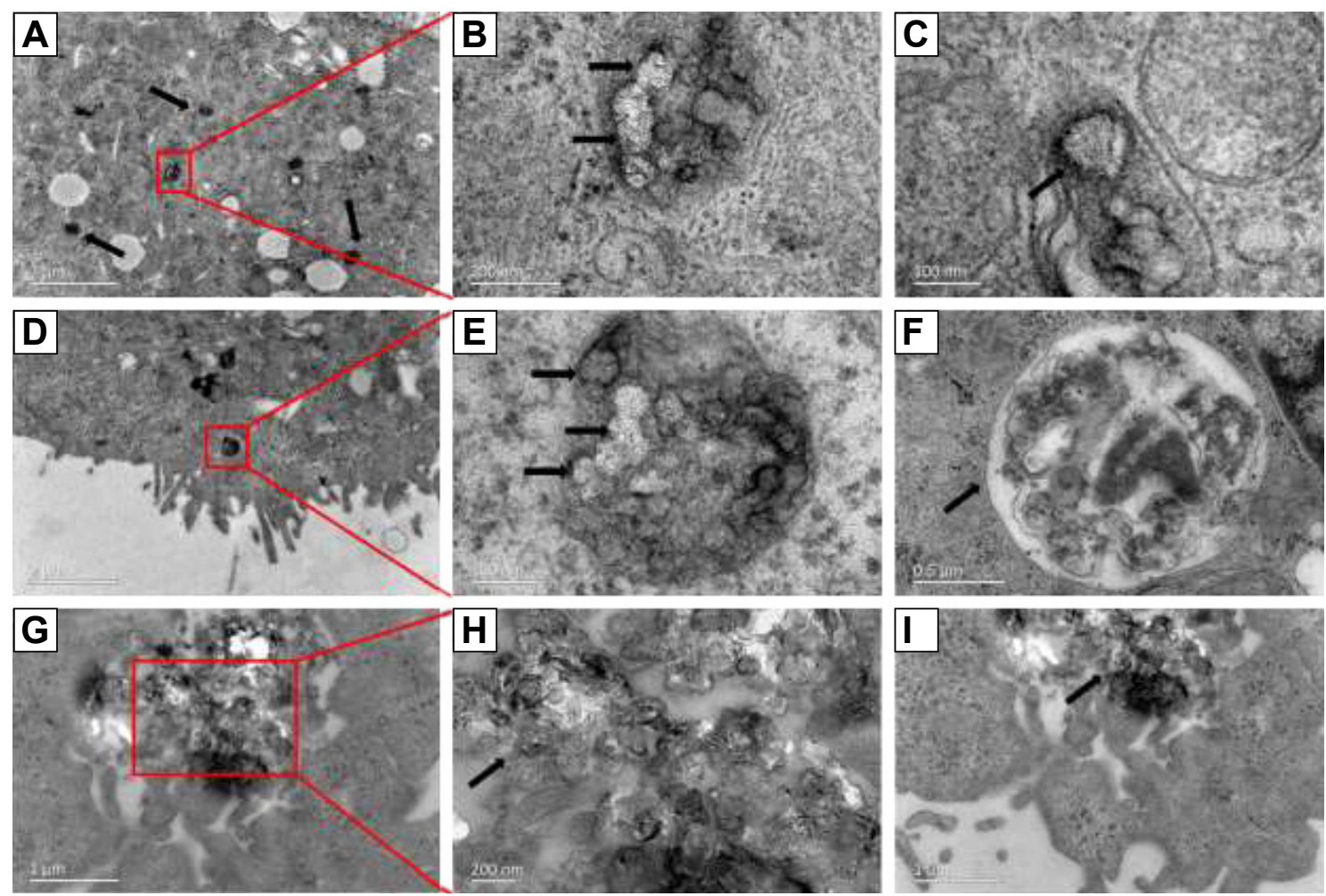

Figure 5 TEM graphs of MDCK cells incubated with $50 \mu \mathrm{g} \mathrm{mL}-1$ SWCNHox suspension at $37^{\circ} \mathrm{C}$ for $24 \mathrm{~h}$. Red rectangle and red lines indicate the enlarged area. Black arrows indicate the internalized SWCNHox. (A, B, D, E) Internalized SWCNHox clustered in an endosomal vesicle; (C) Single spherical SWCNHox was entering a cell; (F) SWCNHox in a lysosome; (G-I) SWCNHox in a multivesicular body.

Abbreviations: TEM, transmission electron microscope; SWCNHox, oxidized single-wall carbon nanohorns. 
A
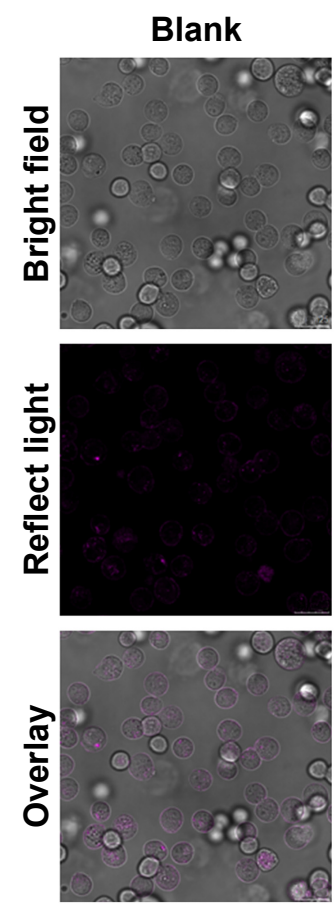

B

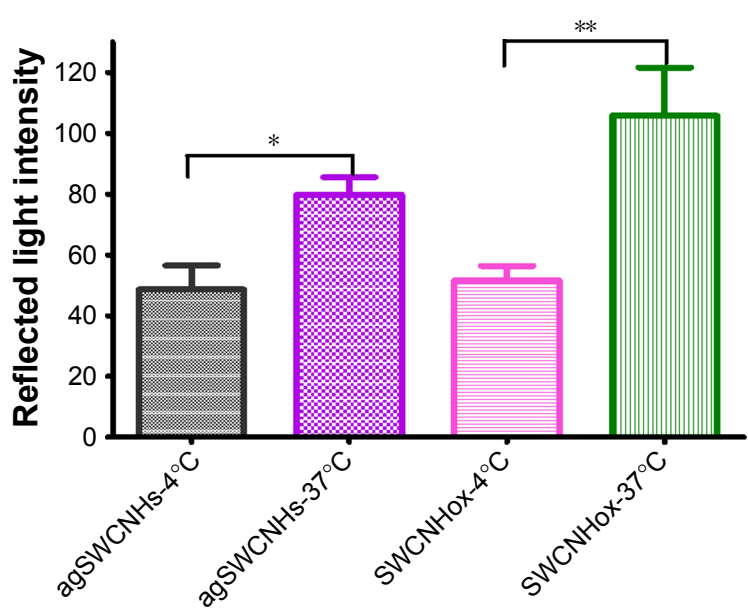

agSWCNHs $-4^{\circ} \mathrm{C}$ agSWCNHs $-37^{\circ} \mathrm{C}$ SWCNHox $-4^{\circ} \mathrm{C}$ SWCNHox $-37^{\circ} \mathrm{C}$
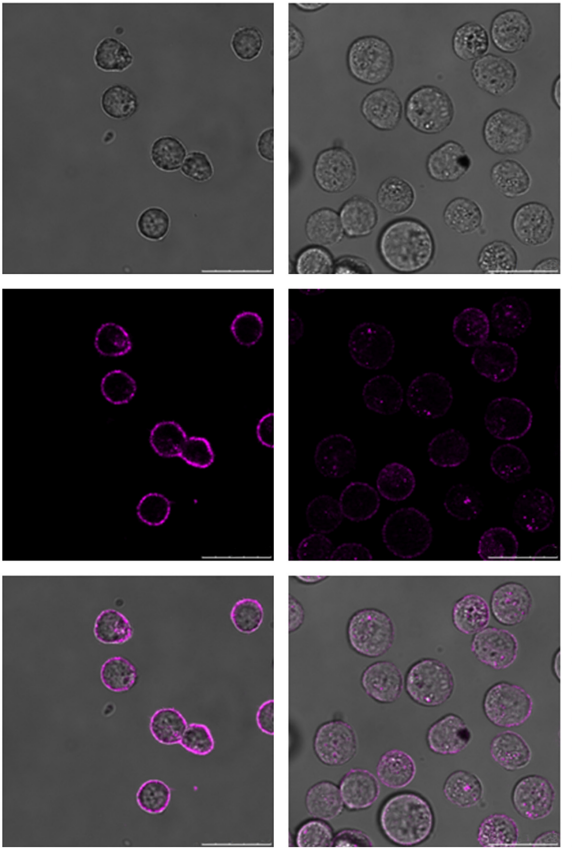
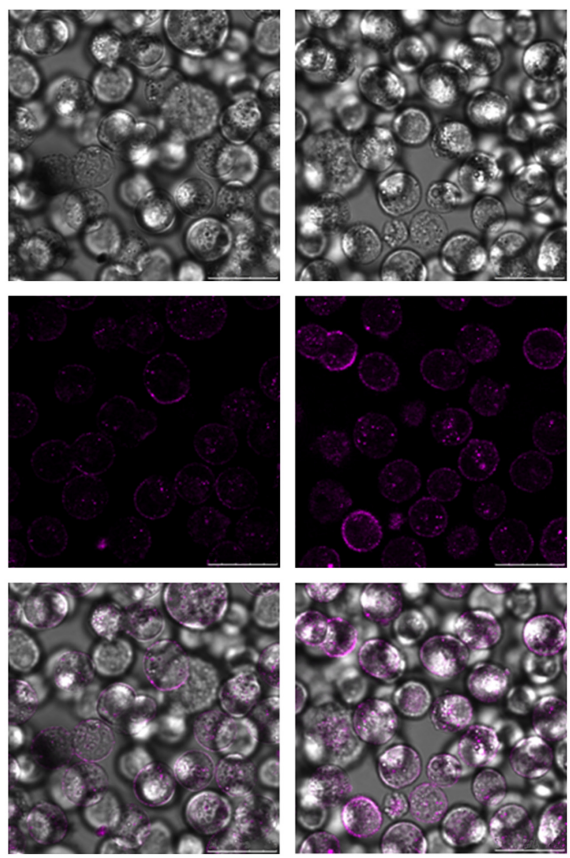

C
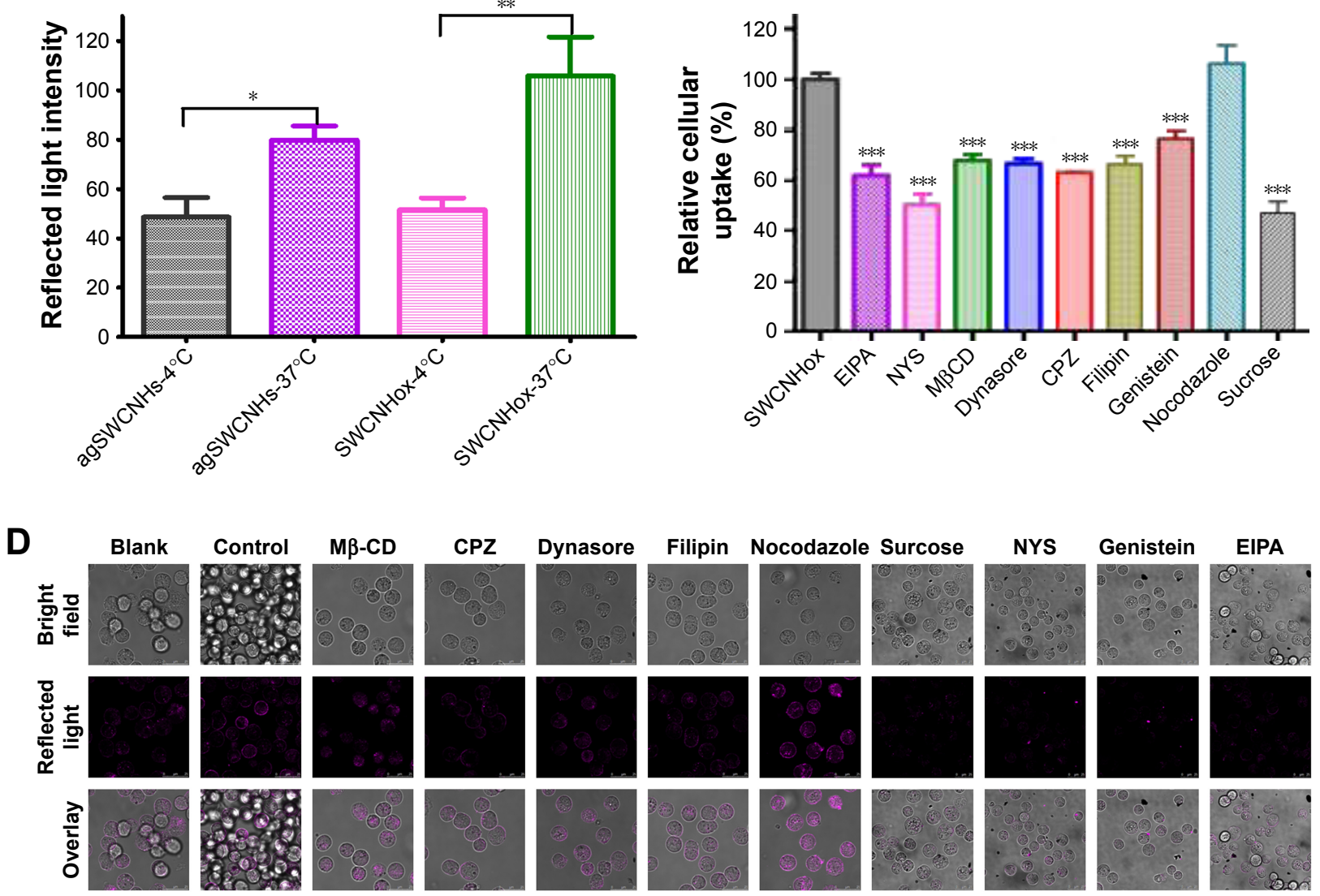

Figure 6 (A) Reflected light confocal microscope images of MDCK cells after incubation with $100 \mu \mathrm{g} \mathrm{mL^{-1 }}$ agSWCNHs or SWCNHox at $4^{\circ} \mathrm{C}$ or $37^{\circ} \mathrm{C}$ for 4 h; (B) The mean intracellular reflected light intensity of MDCK cells exposed to $100 \mu \mathrm{g} \mathrm{mL} L^{-1}$ agSWCNHs or SWCNHox at $4^{\circ} \mathrm{C}$ or $37^{\circ} \mathrm{C}$ for $4 \mathrm{~h}$ analyzed with Leica $\mathrm{Qwin}$ software. $* \mathrm{P}<0.05$, $* * P<0.0$; (C) The percentage of mean intracellular reflect light intensity of MDCK cells exposed to $100 \mu g \mathrm{~mL}^{-1} \mathrm{SWCNHox}$ with different inhibitors analyzed with Leica Qwin software. $* * * P<0.001$; (D) Reflected light confocal microscope images of MDCK cells pre-incubated with different inhibitors for I h, and continued incubation with I00 $\mu \mathrm{g} \mathrm{mL}^{-1}$ SWCNHox together with different inhibitors for another $2 \mathrm{~h}$. Magenta represented the pseudo-color of reflected light of SWCNHs. Scale bars for images in $\mathbf{A}$ and $\mathbf{D}$ are $25 \mu \mathrm{m}$. Abbreviations: SWCNH, single-wall carbon nanohorn; MDCK, Madin-Darby canine kidney; M $\beta C D$, methyl $\beta$-cyclodextrin; agSWCNH, as-grown single-wall carbon nanohorns; SWCNHox, oxidized single-wall carbon nanohorns. 
in endocytosis. ${ }^{40}$ Additionally, dynasore, a cell-permeable inhibitor of dynamin, also exhibited a significantly suppressive effect. ${ }^{41,42}$ Generally, caveolar, CME, and macropinocytosis are responsible for the internalization of particles of different sizes. ${ }^{43,44}$ The pathway studies demonstrated that the endocytosis of SWCNHox may be mediated via multiple mechanisms.

\section{Transcellular demonstration of agSWCNHs, SWCNHox, and F-B- SWCNHox across MDCK cell monolayer Quantitative detection of transported SWCNHs}

Figure 7A shows quantitatively the transport of agSWCNHs, SWCNHox, and F-B-SWCNHox across MDCK cell monolayer at the concentration of $20 \mu \mathrm{g} \mathrm{mL} L^{-1}$ at $37^{\circ} \mathrm{C}$. Though the transported particles increased slightly after oxidation, there were no significant differences among these groups. The transportation of SWCNHox was in a concentration- and time-dependent manner (Figure 7B and C). Though there seems to be no saturation in transport in the experimental condition, the amount of transported SWCNHox was rather limited, and less than $5 \%$ of SWCNHox added to the apical medium was detected in the basolateral compartment after 40-h incubation.

\section{Confocal image series of the transportation of F-B-SWCNHox through MDCK cell monolayer} After incubation with F-B-SWCNHox for $12 \mathrm{~h}$, green fluorescence was seen in the Transwell, indicating that F-B-SWCNHox could be adsorbed and internalized by MDCK cells (Figure 8A). Figure 8B shows the pores on Transwell membrane clearly and some pores filled with green fluorescence, suggesting that F-B-SWCNHox could transcytose across the monolayer. Images taken in $\mathrm{Y}$-axis further validated the conclusion. Green fluorescence (white arrows) was observed in the pores on Transwell membrane
A
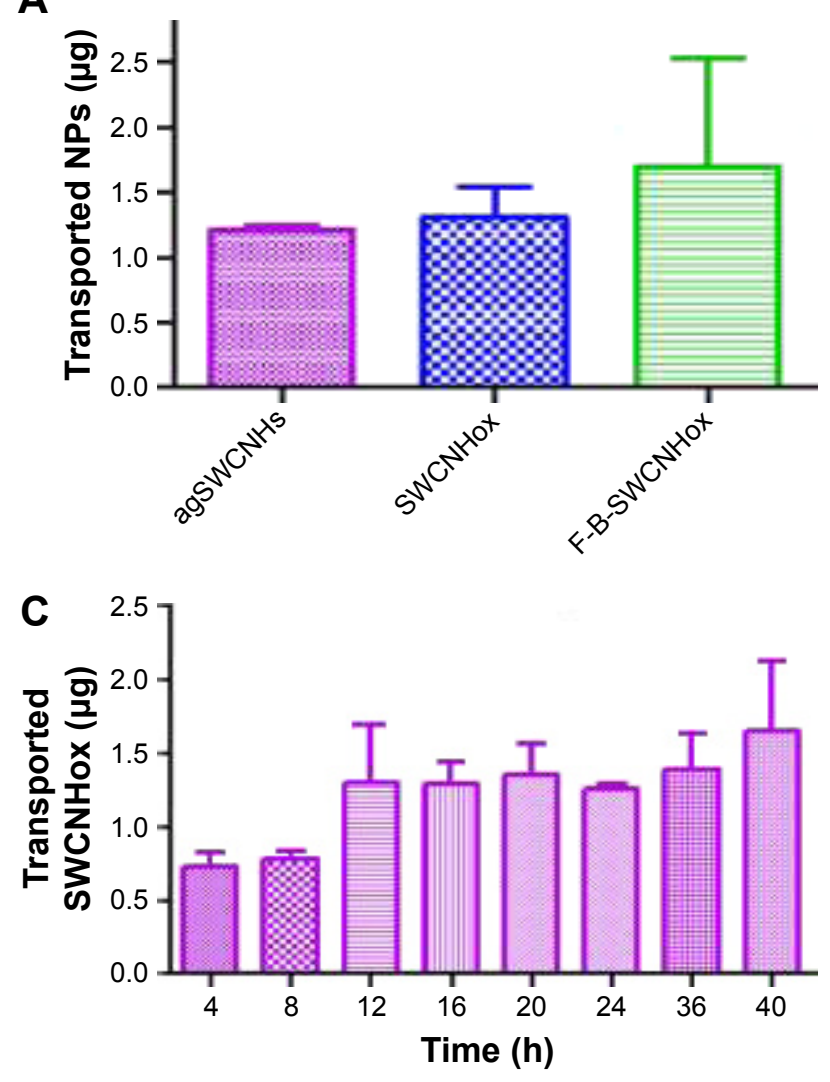

B
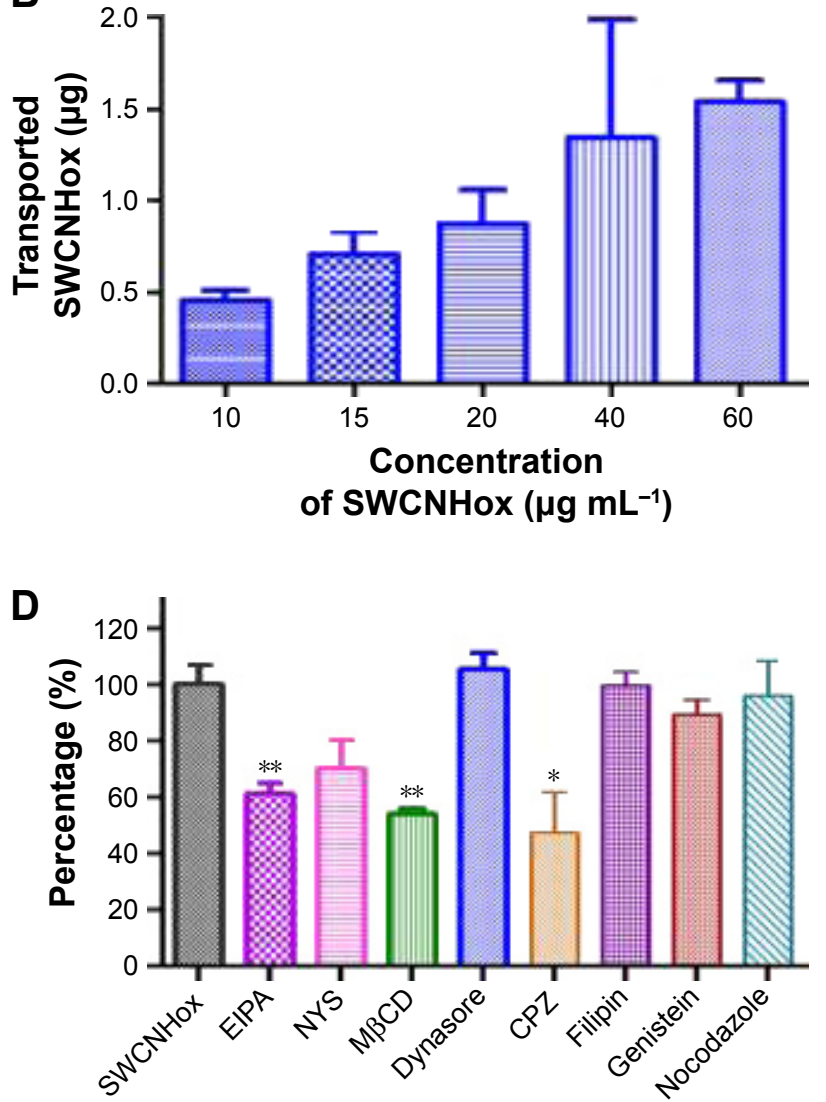

Figure 7 (A) The quantity of transported agSWCNHs, SWCNHox and F-B-SWCNHox across MDCK cell monolayer at a concentration of $20 \mu g$ mL ${ }^{-1}$; (B) The quantity of transported SWCNHox across MDCK cell monolayer with various concentrations; (C) The quantity of SWCNHox transported across MDCK cell monolayer at different time points; (D) Transported SWCNHox across MDCK cell monolayer after incubation with inhibibors for $2 \mathrm{~h}$, all data were compared to the control group treated with SWCNHox alone. Statistical significance was analysed using ANOVA. $* P<0.05, * * p<0.01$. At each time point in A-D, medium in the basolateral chamber was collected and measured with multifunctional microplate reader-optical density method.

Abbreviations: SWCNH, single-wall carbon nanohorn; F-B-SWCNHox, FITC-BSA conjugated SWCNHox; MDCK, Madin-Darby canine kidney; EIPA, 5-(N-ethyl-Nisopropyl)-amiloride; NYS, nystatin; M $\beta C D$, methyl $\beta$-cyclodextrin; CPZ, chlorpromazine. 

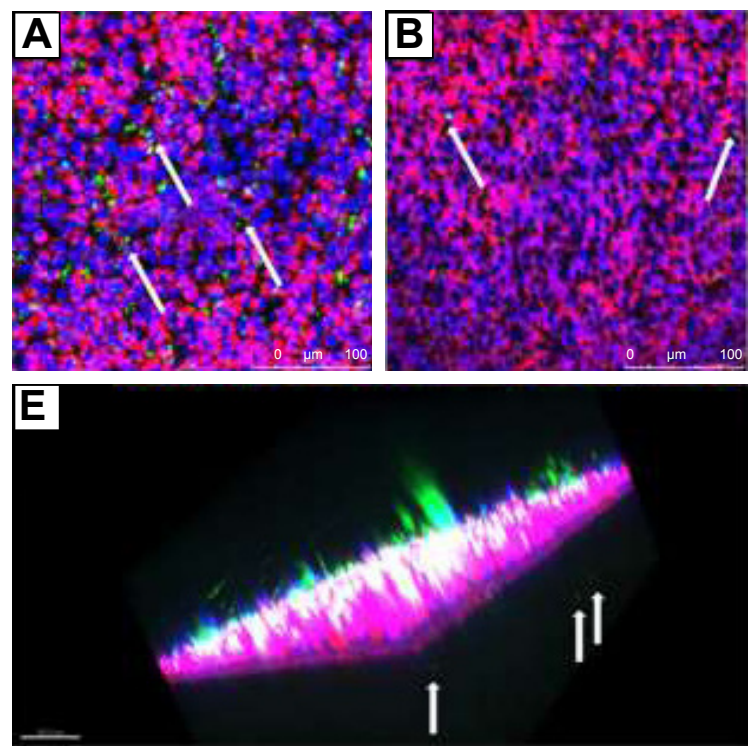
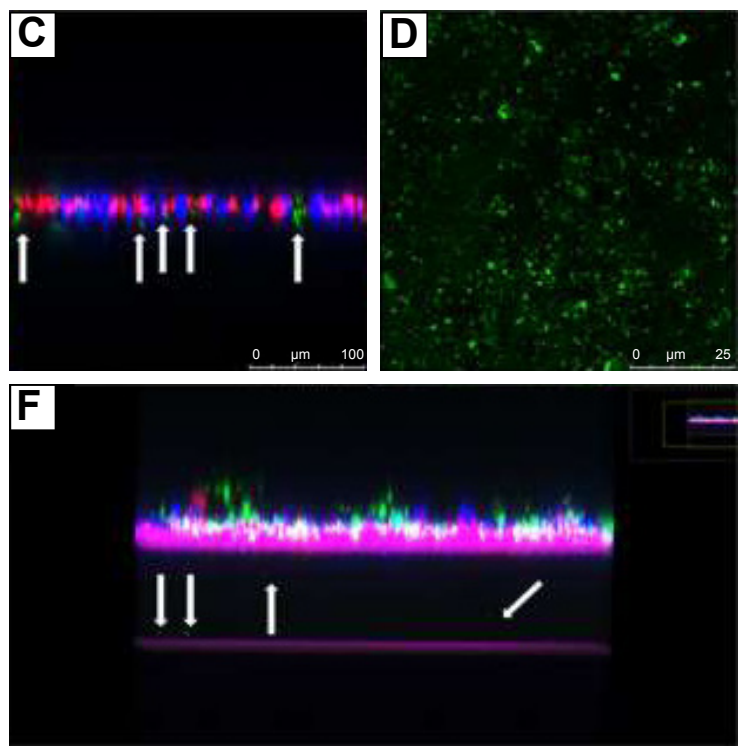

Figure $8 \mathrm{CLSM}$ images of cell monolayer grown on Transwell in z-axis (A), in z-axis (B), and in $y$-axis (C) after incubation with $40 \mu \mathrm{mL} \mathrm{mL}^{-1} \mathrm{~F}$-B-SWCNHox suspensions at $37^{\circ} \mathrm{C}$ for $12 \mathrm{~h}$. (D) Confocal image of the transported F-B-SWCNHox at excitation wavelength of $488 \mathrm{~nm}$; (E, F) Three dimensional reconstructions of MDCK cell monolayer after incubation, observed by CLSM; arrows indicate the transcytosed F-B-SWCNHox. Green represents F-B-SWCNHox, blue represents nuclei, red represents lysosomes, and pink represents the pseudo-color of transwell membrane.

Abbreviations: CLSM, confocal laser scanning microscope; SWCNHox, oxidized single-wall carbon nanohorns; F-B-SWCNHox, FITC-BSA conjugated SWCNHox.

(Figure 8C). Through the confocal image of the transported F-B-SWCNHox after concentration by centrifugation (Figure 8D), it was found that the particles integrated to large clusters without loss of fluorescence signal. Meanwhile, the large size of the particles made it easier for them to be observed directly by confocal imaging. Furthermore, 3D reconstructions of confocal images were conducted (Figure 8E and F). Transported F-B-SWCNHox were seen and exhibited green fluorescence in the gap between Transwell membrane and glass bottle dish (white arrows). These results further proved that F-B-SWCNHox possessed the potential to transport across MDCK cell monolayer.
Confocal image series of MDCK cell monolayer at different distances along the $\mathrm{Z}$-axis from apical side towards basal side after 12-h incubation with F-B-SWCNHox (Figure S5) and the series of this sample along Y-axis (Figure S6) also demonstrated the same finding. These methods directly and simply demonstrated the transport of the SWCNHox across the cell monolayer.

\section{TEM analysis of cell monolayer after transport experiment}

TEM was employed in this study to monitor the MDCK cell monolayer morphology in an effort to define the subcellular
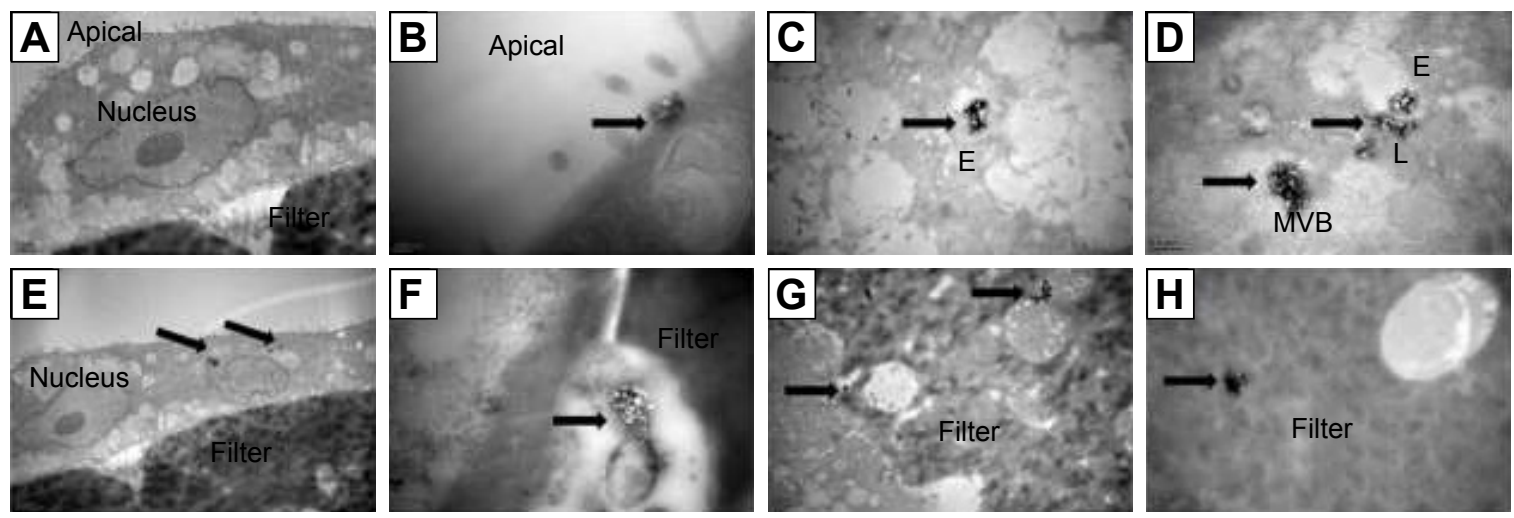

Figure 9 Uptake and transcytosis of SWCNHox in MDCK cell monolayers. Cells were exposed to $20 \mu \mathrm{mL} \mathrm{mL}^{-1}$ SWCNHox in DMEM containing I0\% FBS for $12 \mathrm{~h}$, and cells without any treatment were used as control. Arrows indicate SWCNHox. (A) Control. (B) A cluster of SWCNHox was entering a cell. (C, D) Large numbers of SWCNHox accumulated into a multivesicular body (MVB) in cytoplasm. (E) SWCNHox in lysosomes. (F) A large cluster of SWCNHox was observed outside the cell and inside the filter pore. (G) A few SWCNHox were found between the MDCK monolayer and the filter. In the same image, SWCNHox was also observed in cell synapse growth in the filter hole. (H) SWCNHox adhesion on the filter.

Abbreviations: SWCNH, single-wall carbon nanohorn; SWCNHox, oxidized single-wall carbon nanohorns; DMEM, Dulbecco's Modified Eagle's Medium; FBS, fetal bovine serum; E, endosomes; MVB, multivesicularbodies; L, lysosomes. 
locations of SWCNHox within the MDCK cell monolayer. From the TEM graphs (Figure 9), it was found that SWCNHox were either associated with the cell membrane or internalized inside cells. Typical intracellular locations of SWCNHox included endosomes, multivesicular bodies, and lysosomes, suggesting that SWCNHox mainly trafficked along the endo-lysosomal pathway (Figure 9B-E). Some particles were observed outside the cells, inside the filter pores (Figure 9F and G), or adhered on the filter (Figure 9H); some SWCNHox were found growing in cell synapse in the filter hole (Figure 9G). This evidence proved the successful transport of SWCNHox across the epithelial cell monolayer.

\section{Evaluation of MDCK cell monolayer integrity}

The value of TEER is widely used to evaluate the integrity of tight junctions. ${ }^{45}$ In this work, MDCK monolayers with a
TEER value above $180 \Omega$ were selected for the subsequent studies. ${ }^{32}$ TEER was slightly reduced but still exceeded $180 \Omega$ after incubation with agSWCNHs, SWCNHox, and F-BSWCNHox at $20 \mu \mathrm{g} \mathrm{mL}^{-1}$ for $6 \mathrm{~h}$ (Figure S7A). A similar effect was found at different concentrations of SWCNHox on MDCK monolayer integrity (Figure S7B).

Study of the mechanism of the transcellular process of agSWCNHs and SWCNHox

Though adding samples led to different degrees of reduction, the TEER values of all the sample cells still exceeded $180 \Omega$ after 3-h incubation with $100 \mu \mathrm{g} \mathrm{mL}^{-1}$ SWCNHox and inhibitors (Figure S7C). Figure 7D shows the effects of different inhibitors on SWCNHox transcytosis. CPZ, M $\beta C D$, nystatin, and EIPA depressed the transport of SWCNHox significantly, while filipin, dynasore, genistein, and nocodazole had no effect. This finding demonstrated that the mechanism
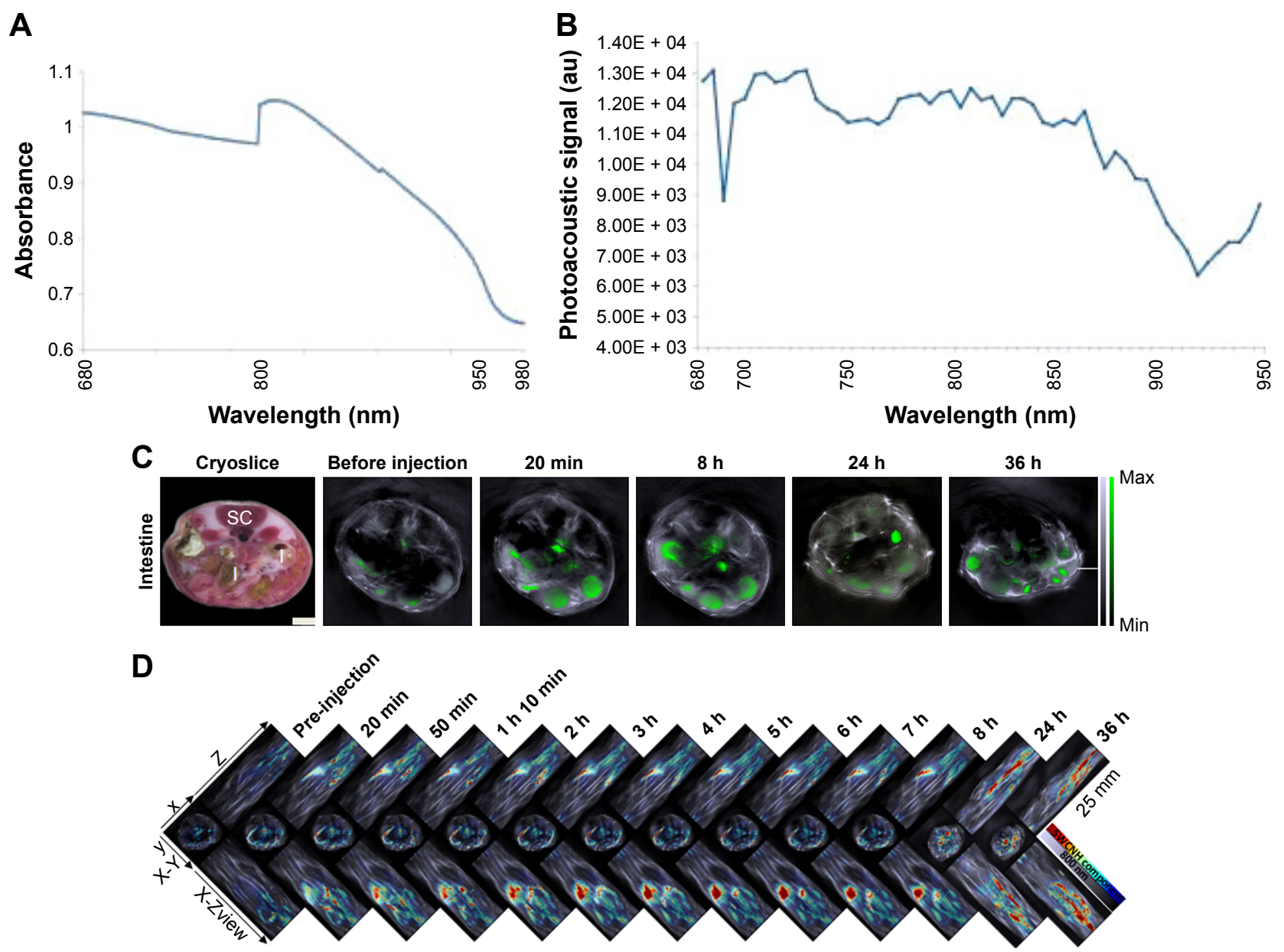

Figure 10 (A) Spectrometer spectrum of SWCNHox; (B) MSOT spectrum of SWCNHox; (C) Image of cryoslice was used as anatomical references: SC=spinal cord, I=intestines. Others depicted MSOT single cross-section images of the intestines, and showed the SWCNHox signal distribution in intestines at multiple time points after oral gavage of SWCNHox. MSOT images displayed a single-wavelength optoacoustic image (grayscale, $800 \mathrm{~nm}$ ) as an anatomical reference with an overlay of multispectrally resolved SWCNHox signal (green). (D) Multiple intensity projections of 3D orthogonal views acquired with the MSOT at multiple time points. SWCNHox shown using a jet color scale superimposed over the grayscale $800 \mathrm{~nm}$ single wavelength images.

Abbreviations: MSOT, fast multispectral optoacoustic tomography; SWCNH, single-wall carbon nanohorn; SWCNHox, oxidized single-wall carbon nanohorns; 3D, threedimensional. 
involved in exocytosis and endocytosis may be different. The inhibiting agent may work on both endocytosis and transcytosis such as CPZ, M $\beta C D$, and EIPA, or only inhibit one of the two processes such as filipin, dynasore, and genistein, or work on neither of the two processes such as nocodazole. Therefore, the transport of SWCNHs was through an active transcellular pathway, involving lipid rafts, clathrin-mediated pathway, and macropinocytosis, as well as multiple pathways at different degrees of involvement.

\section{In vivo monitoring of the interaction between SWCNHox and intestinal epithelium}

From the absorption spectrum (Figure 10A) and the photoacoustic signal of SWCNHox at the wavelengths of 680-950 nm (Figure 10B), six wavelengths (700, 730, 760, 800,850 , and $900 \mathrm{~nm}$ ) were selected to acquire the photoacoustic image. MSOT imaging was used to detect the in vivo biodistribution and transport process of SWCNHs after oral administration in nude mice. As shown in Figure 10C, the signal of SWCNHox in the intestine was observed from $20 \mathrm{~min}$ to $36 \mathrm{~h}$ after the garage. The multiple-intensity projections of $3 \mathrm{D}$ orthogonal views were acquired in a time course (up to $36 \mathrm{~h}$ ) from the MSOT, as shown in Figure 10D. An increased SWCNHox signal was observed around the stomach and in the intestines, with a high degree of colocalization. SWCNHox signal was slowly decreased in stomach and reduced to the background level after $24 \mathrm{~h}$. At detectable levels, almost no SWCNHox could be detected in the blood, liver, spleen, and kidney over the entire time course. In conclusion, SWCNH nanocarriers had a long retention time in the intestinal tract, probably due to the surface adhesion and endocytosis in intestinal epithelium after oral administration.

\section{Discussion}

SWCNHs, a new type of carbon nanomaterials, have unique structural properties with a cone-sharp and hollow structure, and are emerging as one of the promising nanocarriers for biomedical applications such as drug delivery. ${ }^{1-4}$ So far, reports on the SWCNHs have focused on drug release in vitro, tumor-targeting therapy, or thermal treatment after intramuscular injection or tail vein injection in vivo. ${ }^{7}$ The previous studies on the interaction between SWCNHs and cells have mostly emphasized on cellular uptake and intracellular trafficking, but seldom on epithelial cells, although epithelial cell membranes as the typical biological barrier constitute the prime obstacle for the transport of therapeutic agents. ${ }^{14,15}$
In light of these previous findings, this study focused on characterizing the effect of this novel material on the polar epithelium and examining its ability to modulate transcellular transport and its potential in drug delivery.

The results showed a strong bioadhesion property and minimal cytotoxicity to MDCK cells upon 72-h exposure to the SWCNHs at $100 \mu \mathrm{g} \mathrm{mL}^{-1}$ concentration. Most of the SWCNHs accumulated at the surface of cell membranes, and some of the nanovectors could be internalized as evidenced by both probe-free and fluorescence-based methods. As drug delivery vectors, cell-associated SWCNHs, including the internalized, adhered, and agglomerated SWCNHs, are expected to afford greater intracellular drug levels. The significant difference of uptake under various temperature conditions reflected the energy dependence of the endocytosis of SWCNH nanocarriers in MDCK cells. The results obtained with different endocytosis inhibitors showed that the endocytosis process of SWCNHs involved multiple mechanisms such as lipid raftsmediated endocytosis, clathrin-mediated pathway, dynamindependent endocytosis, and macropinocytosis.

Multiple modern techniques were used to visualize the cellular transport of SWCNHs and to unveil the underlying mechanisms. It was found that some of the nanovectors could be transported to the other side of the MDCK cell monolayer. The transportation of SWCNHox across the MDCK cell monolayer occurred in a concentration- and time-dependent manner under trial conditions. Multiple mechanisms were involved in the transcytosis of SWCNHs at varying degrees. The transportation of nanocarriers across the polarized epithelial cellular barriers is one key element for the successful delivery of drug-loaded nanocarriers to achieve an optimal pharmacological action at the pathological sites. $^{22}$

After oral administration, SWCNHox were distributed in the gastrointestinal tract and exhibited a long retention time with negligible levels of SWCNHox leaking into the systemic circulation. Studies at the cellular level have validated the interaction between SWCNHs and epithelial cells. In vivo results further confirmed that SWCNHs can effectively increase their retention time in the intestinal tract, probably through the surface adhesion and endocytosis into the intestinal epithelium, thereby promoting drug absorption. The data of this study supported that SWCNHs could overcome the epithelial barrier and serve as a promising nanovector for an effective drug delivery in vitro and in vivo.

\section{Acknowledgments}

The authors thank Dr Lan Yuan (Medical and Healthy Analytical Center, Peking University) and Dr Bo Xu (The State 
Key Laboratory of Natural and Biomimetic Drugs, School of Pharmaceutical Sciences, Peking University) for their kind help in data acquisition and analysis of laser scanning confocal imaging. They thank Dr Nanyin Han and Dr Xin Chen (both from the Department of Chemical Biology, School of Pharmaceutical Sciences, Peking University) for use of their laboratory facilities to carry out the cell culture experiments. They also thank Dr Rui Wang (Cold Spring Biotech Corp.) and Dr Thomas Sardellaini (Thera Medical $\mathrm{GmbH}$ ) for kindly assisting in MSOT and data analysis. They are extremely grateful to Dr Hua Zhang and Dr Wenbing Dai (both from the Beijing Key Laboratory of Molecular Pharmaceutics and New Drug Delivery Systems, Peking University) for their encouragement and helpful discussion. They acknowledge support from the National Basic Research Program of China (973 program, 2015CB932100) and the National Natural Science Foundation of China (grant no 81603041).

\section{Disclosure}

The authors report no conflicts of interest in this work.

\section{References}

1. Ajima K, Murakami T, Mizoguchi Y, et al. Enhancement of in vivo anticancer effects of cisplatin by incorporation inside single-wall carbon nanohorns. ACS Nano. 2008;2:2057-2064.

2. Murakami T, Fan J, Yudasaka M, et al. Solubilization of single-wall carbon nanohorns using a PEG-doxorubicin conjugate. Mol Pharm. 2006;3:407-414.

3. Murakami T, Ajima K, Miyawaki J, et al. Drug-loaded carbon nanohorns: adsorption and release of dexamethasone in vitro. Mol Pharm. 2004;1:399-405.

4. Xu J, Yudasaka M, Kouraba S, et al. Single wall carbon nanohorn as a drug carrier for controlled release. Chem Phys Lett. 2008;461: 189-192.

5. Nakamura M, Tahara Y, Ikehara Y, et al. Single-walled carbon nanohorns as drug carriers: adsorption of prednisolone and anti-inflammatory effects on arthritis. Nanotechnology. 2011;22:465102.

6. Huang W, Zhang J, Dorn HC, et al. Assembly of single-walled carbon nanohorn supported liposome particles. Bioconjug Chem. 2011;22: 1012-1016.

7. Li N, Zhao Q, Shu C, et al. Targeted killing of cancer cells in vivo and in vitro with IGF-IR antibody-directed carbon nanohorns based drug delivery. Int J Pharm. 2015;478:644-654.

8. Whitney JR, Sarkar S, Zhang J, et al. Single walled carbon nanohorns as photothermal cancer agents. Lasers Surg Med. 2011;43:43-51.

9. Jiang B, Hu L, Shen X, et al. One-step preparation of a water-soluble carbon nanohorn/phthalocyanine hybrid for dual-modality photothermal and photodynamic therapy. ACS Appl Mater Interfaces. 2014;6: 18008-18017.

10. Zhang M, Murakami T, Ajima K, et al. Fabrication of ZnPc/protein nanohorns for double photodynamic and hyperthermic cancer phototherapy. Proc Natl Acad Sci U S A. 2008;105:14773-14778.

11. Miyawaki J, Yudasaka M, Imai H, et al. In vivo magnetic resonance imaging of single-walled carbon nanohorns by labeling with magnetite nanoparticles. Adv Mater. 2006;18:1010-1014.

12. Miyawaki J, Yudasaka M, Imai H, et al. Synthesis of ultrafine $\mathrm{Gd}_{2} \mathrm{O}_{3}$ nanoparticles inside single-wall carbon nanohorns. JPhys Chem B. 2006;110: 5179-5181.
13. Zhu S, Xu G. Single-walled carbon nanohorns and their applications. Nanoscale. 2010;2:2538-2549.

14. Zhang M, Zhou X, Iijima S, et al. Small-sized carbon nanohorns enabling cellular uptake control. Small. 2012;8:2524-2531.

15. Yang M, Zhang MF, Tahara Y, et al. Lysosomal membrane permeabilization: carbon nanohorn-induced reactive oxygen species generation and toxicity by this neglected mechanism. Toxicol Appl Pharmacol. 2014;280:117-126.

16. Tahara Y, Miyawaki J, Zhang M, et al. Histological assessments for toxicity and functionalization-dependent biodistribution of carbon nanohorns. Nanotechnology. 2011;22:265106.

17. Miyawaki J, Matsumura S, Yuge R, et al. Biodistribution and ultrastructural localization of single-walled carbon nanohorns determined in vivo with embedded $\mathrm{Gd}_{2} \mathrm{O}_{3}$ labels. ACS Nano. 2009;3:1399-1406.

18. Tahara Y, Nakamura M, Yang M, et al. Lysosomal membrane destabilization induced by high accumulation of single-walled carbon nanohorns in murine macrophage RAW 264.7. Biomaterials. 2012;33(9):2762-2769.

19. Yang M, Wada M, Zhang M, et al. A high poly(ethylene glycol) density on graphene nanomaterials reduces the detachment of lipid-poly(ethylene glycol) and macrophage uptake. Acta Biomater. 2013;9(1):4744-4753.

20. Orecchioni M, Bedognetti D, Sgarrella F, et al. Impact of carbon nanotubes and graphene on immune cells. J Transl Med. 2014;12:138.

21. Lacotte S, García A, Décossas M, et al. Interfacing functionalized carbon nanohorns with primary phagocytic cells. Adv Mater. 2008;20: 2421-2426.

22. Rabane JM, Aoun V, Elkin I, et al. Drug-loaded nanocarriers: passive targeting and crossing of biological barriers. Curr Med Chem. 2012; 19(19):3070-3102.

23. Nichols JW, Bae YH. Odyssey of a cancer nanoparticle: from injection site to site of action. Nano Today. 2012;7:606-618.

24. Ghaffarian R, Bhowmick T, Muro S. Transport of nanocarriers across gastrointestinal epithelial cells by a new transcellular route induced by targeting ICAM-1. J Control Release. 2012;163(1):25-33.

25. Rytting E, Nguyen J, Wang X, et al. Biodegradable polymeric nanocarriers for pulmonary drug delivery. Expert Opin Drug Deliv. 2008;5(6):629-639.

26. Tuma P, Hubbard AL. Transcytosis: crossing cellular barriers. Physiol Rev. 2003;83(3):871-932.

27. Ghaffarian R, Muro S. Models and methods to evaluate transport of drug delivery systems across cellular barriers. J Vis Exp. 2013;80:e50638.

28. Liu M, Zhang J, Zhu X, et al. Efficient mucus permeation and tight junction opening by dissociable "mucus-inert" agent coated trimethyl chitosan nanoparticles for oral insulin delivery. $J$ Control Release. 2016;222:67-77.

29. Kaiser M, Pereira S, Pohl L, et al. Chitosan encapsulation modulates the effect of capsaicin on the tight junctions of MDCK cells. Sci Rep. 2015;5:10048.

30. Yu C, He B, Xiong M, et al. The effect of hydrophilic and hydrophobic structure of amphiphilic polymeric micelles on their transport in epithelial MDCK cells. Biomaterials. 2013;34:6284-6298.

31. Zhao S, Dai W, He B, et al. Monitoring the transport of polymeric micelles across MDCK cell monolayer and exploring related mechanisms. J Control Release. 2012;158:413-423.

32. He B, Jia Z, Du W, et al. The transport pathways of polymer nanoparticles in MDCK epithelial cells. Biomaterials. 2013;34: 4309-4326.

33. Li N, Wang Z, Zhao K, et al. Synthesis of single-wall carbon nanohorns by arc-discharge in air and their formation mechanism. Carbon. 2010;48:1580-1585.

34. Zhang M, Yudasaka M, Ajima K, et al. Light-assisted oxidation of single-walled carbon nanohorns for abundant creation of oxygenated groups that enable chemical modifications with proteins to enhance biocompatibility. ACS Nano. 2007;1:265-272.

35. Kim BS, Oh JM, Kim KS, et al. BSA-FITC-loaded microcapsules for in vivo delivery. Biomaterials. 2009;30:902-909. 
36. Dakwar GR, Hammad IA, Popov M, et al. Delivery of proteins to the brain by bolaamphiphilic nano-sized vesicles. J Control Release. 2012;160:315-321.

37. Ye D, Raghnaill MN, Bramini M, et al. Nanoparticle accumulation and transcytosis in brain endothelial cell layers. Nanoscale. 2013;5: 11153-11165.

38. Salvati A, Åberg C, Dos Santos T, et al. Experimental and theoretical comparison of intracellular import of polymeric nanoparticles and small molecules: toward models of uptake kinetics. Nanomedicine. 2011;7: $818-826$.

39. Conner SD, Schmid SL. Regulated portals of entry into the cell. Nature. 2003;422:37-44.

40. Ivanov AI, Nusrat A, Parkos CA. Endocytosis of epithelial apical junctional proteins by a clathrin-mediated pathway into a unique storage compartment. Mol Biol Cell. 2004;15:176-188.
41. Macia E, Ehrlich M, Massol R, et al. Dynasore, a cell-permeable inhibitor of dynamin. Dev Cell. 2006;10:839-850.

42. Bannunah AM, Vllasaliu D, Lord J, et al. Mechanisms of nanoparticle internalization and transport across an intestinal epithelial cell model: effect of size and surface charge. Mol Pharm. 2014;11:4363-4373.

43. Li SX, Wang K, Shi YJ, et al. Novel biological functions of ZIF-NP as a delivery vehicle: high pulmonary accumulation, favorable biocompatibility and improved therapeutic outcome. Adv Funct Mater. 2016;26:2715-2727.

44. Nel AE, Madler L, Velegol D, et al. Understanding biophysicochemical interactions at the nano-bio interface. Nat Mater. 2009;8:543-557.

45. Harhaj NS, Antonetti DA. Regulation of tight junctions and loss of barrier function in pathophysiology. Int J Biochem Cell Biol. 2004;36: $1206-1237$.
International Journal of Nanomedicine

\section{Publish your work in this journal}

The International Journal of Nanomedicine is an international, peerreviewed journal focusing on the application of nanotechnology in diagnostics, therapeutics, and drug delivery systems throughout the biomedical field. This journal is indexed on PubMed Central, MedLine, CAS, SciSearch $\AA$, Current Contents ${ }^{\circledR} /$ Clinical Medicine,

\section{Dovepress}

Journal Citation Reports/Science Edition, EMBase, Scopus and the Elsevier Bibliographic databases. The manuscript management system is completely online and includes a very quick and fair peer-review system, which is all easy to use. Visit http://www.dovepress.com/ testimonials.php to read real quotes from published authors. 